\title{
Extent of Spinal Cord Decompression in Motor Complete (American Spinal Injury Association Impairment Scale Grades A and B) Traumatic Spinal Cord Injury Patients: Post-Operative Magnetic Resonance Imaging Analysis of Standard Operative Approaches
}

\author{
Bizhan Aarabi, ${ }^{1,3}$ Joshua Olexa, Timothy Chryssikos, Samuel M. Galvagno,,3 David S. Hersh, \\ Aaron Wessell, ${ }^{1}$ Charles Sansur,, Gary Schwartzbauer, ${ }^{1,3}$ Kenneth Crandall, \\ Kathirkamanathan Shanmuganathan,,4 J. Marc Simard, Harry Mushlin, Mathew Kole,, Elizabeth Le, \\ Nathan Pratt,' Gregory Cannarsa, Cara D. Lomangino, Maureen Scarboro, ${ }^{3}$ Carla Aresco, and Brian Curry ${ }^{3}$
}

\begin{abstract}
Although decompressive surgery following traumatic spinal cord injury (TSCI) is recommended, adequate surgical decompression is rarely verified via imaging. We utilized magnetic resonance imaging (MRI) to analyze the rate of spinal cord decompression after surgery. Pre-operative (within $8 \mathrm{~h}$ of injury) and post-operative (within $48 \mathrm{~h}$ of injury) MRI images of 184 motor complete patients (American Spinal Injury Association Impairment Scale [AIS] grade A =119, AIS grade $\mathrm{B}=65$ ) were reviewed to verify spinal cord decompression. Decompression was defined as the presence of a patent subarachnoid space around a swollen spinal cord. Of the 184 patients, $100(54.3 \%)$ underwent anterior cervical discectomy and fusion (ACDF), and 53 of them also underwent laminectomy. Of the 184 patients, 55 (29.9\%) underwent anterior cervical corpectomy and fusion (ACCF), with (26 patients) or without (29 patients) laminectomy. Twenty-nine patients (16\%) underwent stand-alone laminectomy. Decompression was verified in 121 patients $(66 \%)$. The rates of decompression in patients who underwent ACDF and ACCF without laminectomy were $46.8 \%$ and $58.6 \%$, respectively. Among these patients, performing a laminectomy increased the rate of decompression ( $72 \%$ and $73.1 \%$ of patients, respectively). Twenty-five of $29(86.2 \%)$ patients who underwent a stand-alone laminectomy were found to be successfully decompressed. The rates of decompression among patients who underwent laminectomy at one, two, three, four, or five levels were $58.3 \%, 68 \%, 78 \%, 80 \%$, and $100 \%$, respectively $(p<0.001)$. In multi-variate logistic regression analysis, only laminectomy was significantly associated with successful decompression (odds ratio 4.85; 95\% confidence interval 2.210.6; $p<0.001$ ). In motor complete TSCI patients, performing a laminectomy significantly increased the rate of successful spinal cord decompression, independent of whether anterior surgery was performed.
\end{abstract}

Keywords: ASIA Impairment Scale; decompression; MRI; spinal cord injury; trauma

\section{Introduction}

NVESTIGATORS HAVE SHOWN that continued spinal cord compression (SCC) following experimental or traumatic spinal cord injury (TSCI) negatively affects neurological outcome, including motor and overall functional status. ${ }^{1-6}$ Magnetic resonance imag- ing (MRI) and computed tomography (CT) myelogram remain the current standards for demonstrating $\mathrm{SCC}{ }^{7}$ In the most recent studies of the timing of operative intervention in TSCI, candidates for decompressive surgery were selected based on SCC as revealed primarily by $\mathrm{T} 2$ weighted image (T2WI) or short tau inversion recovery (STIR) sequences on MRI. ${ }^{7-10}$ Decompressive surgery

\footnotetext{
${ }^{1}$ Department of Neurosurgery, ${ }^{2}$ Department of Anesthesiology, ${ }^{3}$ R. Adams Cowley Shock Trauma Center, ${ }^{4}$ Department of Radiology, University of Maryland School of Medicine, Baltimore, Maryland.

${ }^{5}$ Walter Reed National Military Medical Center, Bethesda, Maryland.

(C) Bizhan Aarabi et al., 2018; Published by Mary Ann Liebert, Inc. This Open Access article is distributed under the terms of the Creative Commons License (http://creativecommons.org/licenses/by/4.0), which permits unrestricted use, distribution, and reproduction in any medium, provided the original work is properly credited.
} 
was carried out in those patients with MRI evidence of continued SCC before or after successful closed reduction in the studies of Vale and colleagues, ${ }^{10}$ Papadopoulos and colleagues, ${ }^{7}$ and Fehlings and colleagues, ${ }^{8}$ Vaccaro and colleagues ${ }^{9}$ also performed randomization after the demonstration of SCC by MRI. Nevertheless, although the role of decompression following TSCI is widely acknowledged, we argue that research into the surgical management of TSCI and its long-term outcome is potentially confounded by lack of postoperative confirmation of actual decompression following operative intervention. Without such studies, the exact definition of "decompression" remains uncertain, and as a result, the most effective techniques for achieving it remain unclear. ${ }^{7-26}$

In a 2007 evidence-based systematic review of traumatic subaxial cervical spine injuries, Dvorak and colleagues ${ }^{27}$ developed an algorithm recommending a stand-alone anterior approach for most compression, burst, and distraction injuries, and a posterior or combined anterior and posterior approach for translation/rotation injuries. Their report does not comment on the relationship between operative approach and the extent of spinal cord decompression. In 2017, Aarabi and colleagues ${ }^{28}$ reported that the extent of decompression as confirmed by post-operative MRI influenced grade conversion in American Spinal Injury Association Impairment Scale (AIS) grade A-C patients. We therefore argue that the most effective strategy for achieving true decompression must follow not only the evidence-based algorithm developed by Dvorak and colleagues, ${ }^{27}$ but also one that increases the likelihood of complete spinal cord decompression. Without such data, ongoing debates regarding the most effective surgical approach to the injured spinal cord in a given setting - whether anterior/posterior/combinationare insufficiently informed. Here, we tested the hypothesis that in motor complete subaxial TSCI patients undergoing decompressive surgery, operative technique determines the extent of spinal cord decompression.

\section{Methods}

In this retrospective analysis of prospectively collected data, the primary outcome was complete spinal cord decompression on postoperative MRI studies, defined as a continuous column of CSF anterior and posterior to the spinal cord on T2WI or STIR sagittal imaging.

\section{Cohort}

From January 2001 through December 2016, over a 16-year period, 1927 patients with blunt subaxial cervical TSCI were admitted to a level I trauma center. Of this number, 184 patients were screened, selected, and included in this study. Patients were age 16 years or older, and based on the International Standards for Neurological and Functional Classification of Spinal Cord Injury (ISNCSCI $^{29}$ were classified as either AIS grade A or B. Good quality pre- and post-operative CT and MRI studies were available for all patients. The subjects underwent surgery for their injuries and were followed in the intensive or intermediate care unit until discharge to a rehabilitation center or death. Excluded patients included those with AIS grades C and D or non-testable (NT; 832 patients), those with non-operative management of their subaxial cervical spine and spinal cord injuries (509 patients), and those with no or poor imaging studies (197 patients). Also excluded were patients with penetrating (gunshot wound or sharp object) SCI (68 patients; Fig. 1).

Variables including patient demographics, injury mechanism, and severity (Glasgow Coma Scale Score (GCS), Injury Severity Score (ISS), evidence of shock or hypoxemia) were recorded. ${ }^{30} \mathrm{We}$ determined American Spinal Injury Association (ASIA) motor

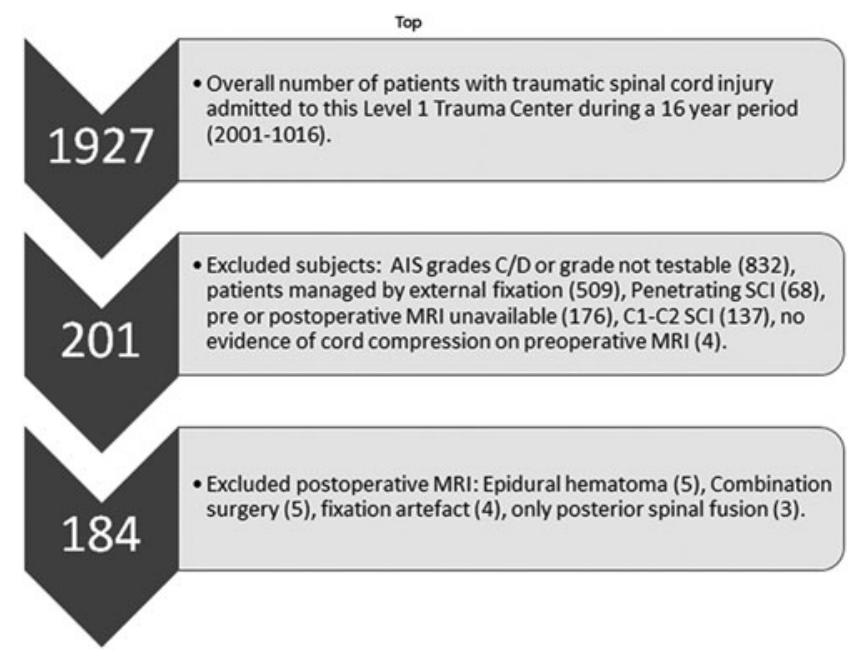

FIG. 1. Flow diagram indicating the selection criteria for 184 American Spinal Injury Association Impairment Scale (AIS) grades A and B subaxial cervical spine traumatic spinal cord injury patients who had decompressive surgery following trauma.

score and ASIA Impairment Scale (AIS) grade at admission and following operative intervention. ${ }^{29,31}$ Midsagittal canal diameter and the height of the subaxial cervical spine were measured to control for congenital spinal stenosis. ${ }^{32,33}$ The fracture/dislocation morphology was classified according to the AOSpine subaxial cervical spine injury classification system. ${ }^{34}$ Surgical management of subaxial cervical spine fracture dislocations was compatible with the scheme used in the randomized prospective trial of Vaccaro and colleagues $^{9}$ and the management algorithm of Dvorak and colleagues ${ }^{27}$ We reviewed post-operative CT and MRI studies in order to determine the surgical technique (i.e., stand-alone anterior cervical discectomy and fusion $[\mathrm{ACDF}]$, anterior cervical corpectomy and fusion $[\mathrm{ACCF}]$, or laminectomy, or in combination). Using the T2WI or STIR sequences, we measured pre-operative and postoperative intramedullary lesion length (IMLL) ${ }^{28,35}$ and determined the state of (obliteration or patency) the subarachnoid space (SAS). ${ }^{28}$ The study started following Investigational Review Board approval of the research proposal.

\section{Initial rescue, resuscitation, and imaging studies}

Patients were initially searched and rescued from the scene of the accident $^{36}$ by emergency medical technicians. Trauma victims were transferred to the Trauma Resuscitation Unit (TRU), backboarded, and chin-strapped. ${ }^{28,37,38}$ The median time between injury and arrival to TRU for 183 patients was $1.1 \mathrm{~h}$, and the scene time was unknown for one patient. The mean scene time in 140 patients who were directly transferred to the TRU was $1 \pm 0.5 \mathrm{~h}$ (median 1.0; range $0.2-3.0 \mathrm{~h}) .^{28}$ In 43 patients who were transferred to the TRU from another facility, the time to arrival was $9.1 \pm 10 \mathrm{~h}$ (median 5.0; range $3.5-53.5 \mathrm{~h}$ ). In the TRU, primary and secondary surveys were performed before neurosurgical consultation. Following resuscitation, the patients were sent for CT and MRI of the cervical spine. Pre-operative multi-planar CT of head, chest, abdomen, pelvis, and spine was performed after a mean of $4.1 \pm 7.0 \mathrm{~h}$ (median 2.1 ; range $0.5-57.5 \mathrm{~h}$ ) from injury. The exact delay from injury to CT studies was unknown in one patient. Multi-planar multi-sequence preoperative MRI images were acquired a mean of $8.4 \pm 8.0 \mathrm{~h}$ (median 6.0 ; range $1.7-57.5 \mathrm{~h}$ ) from injury. MRI was acquired either before or after closed cervical traction reduction in some patients. ${ }^{28,39}$ Post-operative MRI scans were acquired $48.9 \pm 30.7 \mathrm{~h}$ following injury (median $27 \mathrm{~h}$; range $12-150 \mathrm{~h}$ ). ${ }^{28,37}$ For one patient, the time 
interval between injury to pre-operative and post-operative MRI studies was unknown.

\section{Normal anatomy, injury morphology, and instability}

We controlled for congenital spinal stenosis by calculating the mean mid-sagittal A-P diameter of the subaxial cervical spine at three different segmental levels (Fig. 2), applying the methodology recommended by Furlan and colleagues. ${ }^{33}$ Additionally, the height of the subaxial cervical spine was measured from the C2-T1 vertebrae. The AOSpine subaxial cervical spine classification system was used in order to determine injury morphology (Fig. 3) ${ }^{34}$ In this system, compression fractures are classified as types A3 or A4, distraction injuries as types B2 or B3, and injuries associated with translation as type $\mathrm{C}$. To determine fracture/dislocation instability we applied the checklists of White and Panjabi ${ }^{40}$ or Vaccaro and colleagues. $^{41}$

\section{Intramedullary lesion length and verification of spinal cord decompression}

Intramedullary lesion length (IMLL) was measured on preoperative and post-operative MRI (T2WI or STIR) images

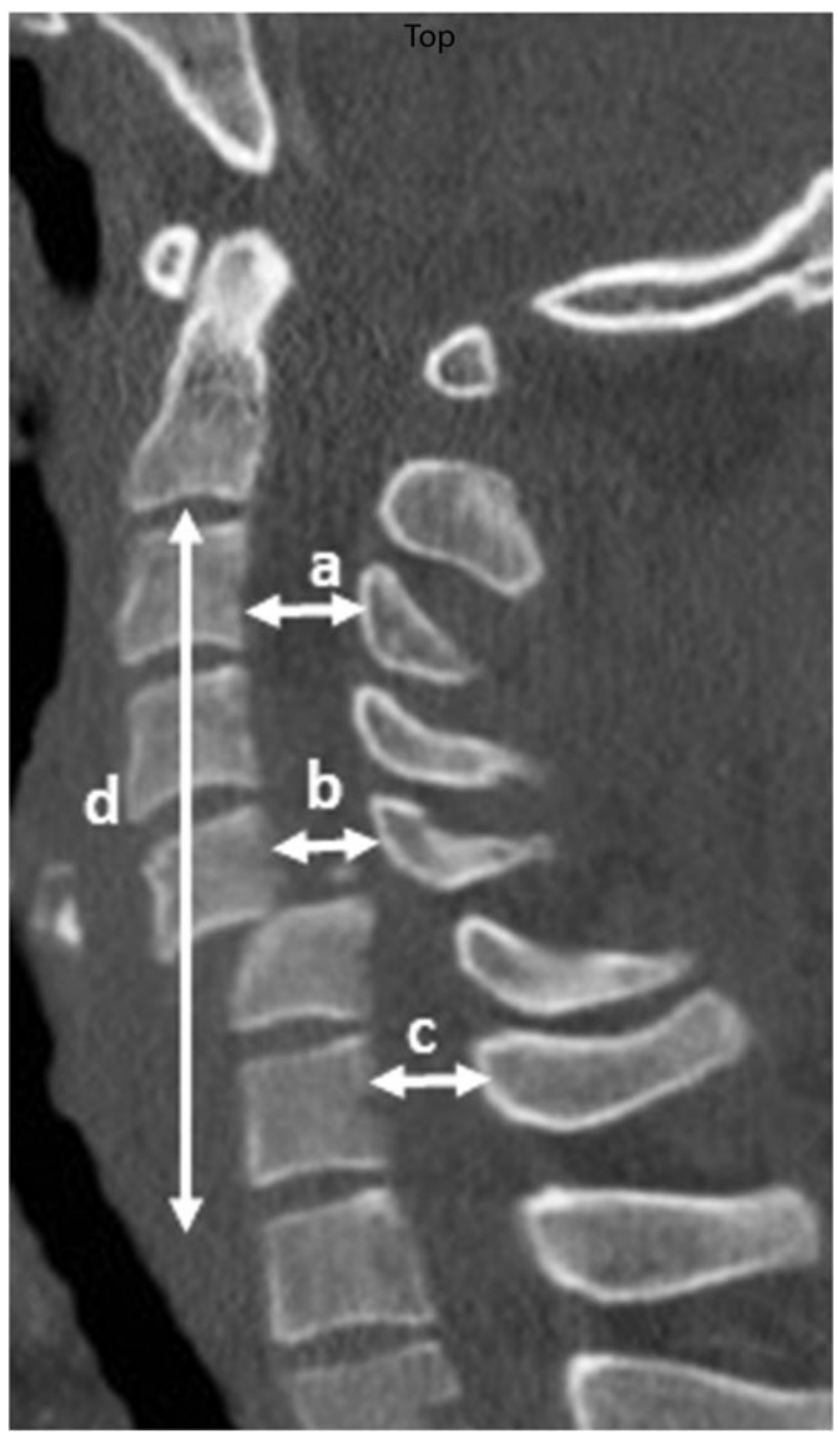

FIG. 2. Midsagittal plane of CT scan from subaxial cervical spine indicating methodology of measurements of sagittal diameter at three segmental levels and the subaxial cervical spine height from C2-T1.
(Fig. 4) ${ }^{28,35,37,39}$ The mean time from trauma to pre-operative MRI was $8.4 \pm 8.0 \mathrm{~h}$ (median 6.0 ; range $1.7-57.5 \mathrm{~h}$ ). The mean time from injury to post-operative MRI was $48.9 \pm 30.7 \mathrm{~h}$ (median 37 ; range $12-150 \mathrm{~h}){ }^{28,39}$ For one patient, the exact time of MRI acquisition following trauma was not recorded. IMLL on pre-operative and post-operative MRI was recorded as the mean of the measured values by four blinded investigators: the principal investigator (B.A.), a trauma neuroradiologist (K.S.), a spine fellowship certified neurosurgeon (K.C.), and a neurotrauma fellowship trained neurosurgeon (G.S.). Decompression was verified by a spine fellowship trained neurosurgeon (C.S.) and a neurotrauma fellowship trained neurosurgeon (G.S.). If there was disagreement between the two raters, the principal investigator (B.A.) served to resolve the discrepancy.

\section{Surgical intervention and technique}

Decompressive surgery was performed a mean of $21.5 \pm 20.8 \mathrm{~h}$ (median 14; range 4.0-136.8 h) following trauma by one of 14 board -certified neurosurgeons (five were spine-fellowship trained). When appropriate, certain patients underwent attempted closed reduction by cervical traction prior to operative intervention. Whether or not reduction was achieved, all pre-operative candidates had evidence of spinal cord compression as indicated by deformation and effacement of SAS at the injury epicenter, and either rostrally or caudally to it. ${ }^{28}$ The objective of surgery was anatomical alignment and internal fixation (anterior, posterior, or a combination of anterior and posterior) of the subaxial cervical spine and decompression of the spinal cord. ${ }^{28}$ There was no policy or guidelines for surgical procedures. Each neurosurgeon applied his preferred surgical techniques to obtain decompression and the most secure internal fixation. ${ }^{28,38}$ The five common operative techniques chosen by surgeons were: 1) ACDF (one to three skeletal segments); 2) ACCF (one or two skeletal segments); 3) ACDF in association with laminectomy (one to five levels) with or without posterior spinal fusion; 4) ACCF and laminectomy (one to five levels); and 5) laminectomy (two to five levels) with or without posterior spinal fusion. The surgical techniques used by the 14 neurosurgeons were compatible with the recommended surgical approaches reported previously by Vaccaro and colleagues ${ }^{9}$ and Dvorak and colleagues $^{27}$ (Fig. 5).

\section{Steroid protocol}

From 2001 through 2010 we administered methylprednisolone ( $30 \mathrm{mg} / \mathrm{kg}$ in $15 \mathrm{~min}$ within the $1 \mathrm{st} \mathrm{h}$ and $5.4 \mathrm{mg} / \mathrm{kg} / \mathrm{h}$ for the next $23 \mathrm{~h})^{42}$ to all patients with TSCI. Infusion started within the first $8 \mathrm{~h}$ of trauma. After 2010, this steroid protocol was abandoned at our institution. $^{43}$

\section{Critical care and hospital length of stay}

Following surgery, the patients were kept in the intensive or intermediate care units until discharge or death. ${ }^{28,37,39}$ Fifteen $(8.4 \%)$ patients died during their acute care in this trauma center. For the 169 patients who were discharged to a rehabilitation center, the mean hospital length of stay was $24.2 \pm 8$ days (median 19.1; range 3.3-127.5 days). The mean survival for the 15 patients who died was $17.5 \pm 15.9$ days (median 12.3 days; range 3.3-59.6 days).

\section{Statistical analysis}

Descriptive statistics were calculated. Unpaired $t$-tests and Wilcoxon rank sum tests were used to assess parametrically and non-parametrically distributed variables, respectively. Univariate logistic regression was performed, followed by multi-variable logistic regression to identify variables independently associated with the outcome of successful decompression. Analysis of variance was performed. Variables for the multi-variate regression 


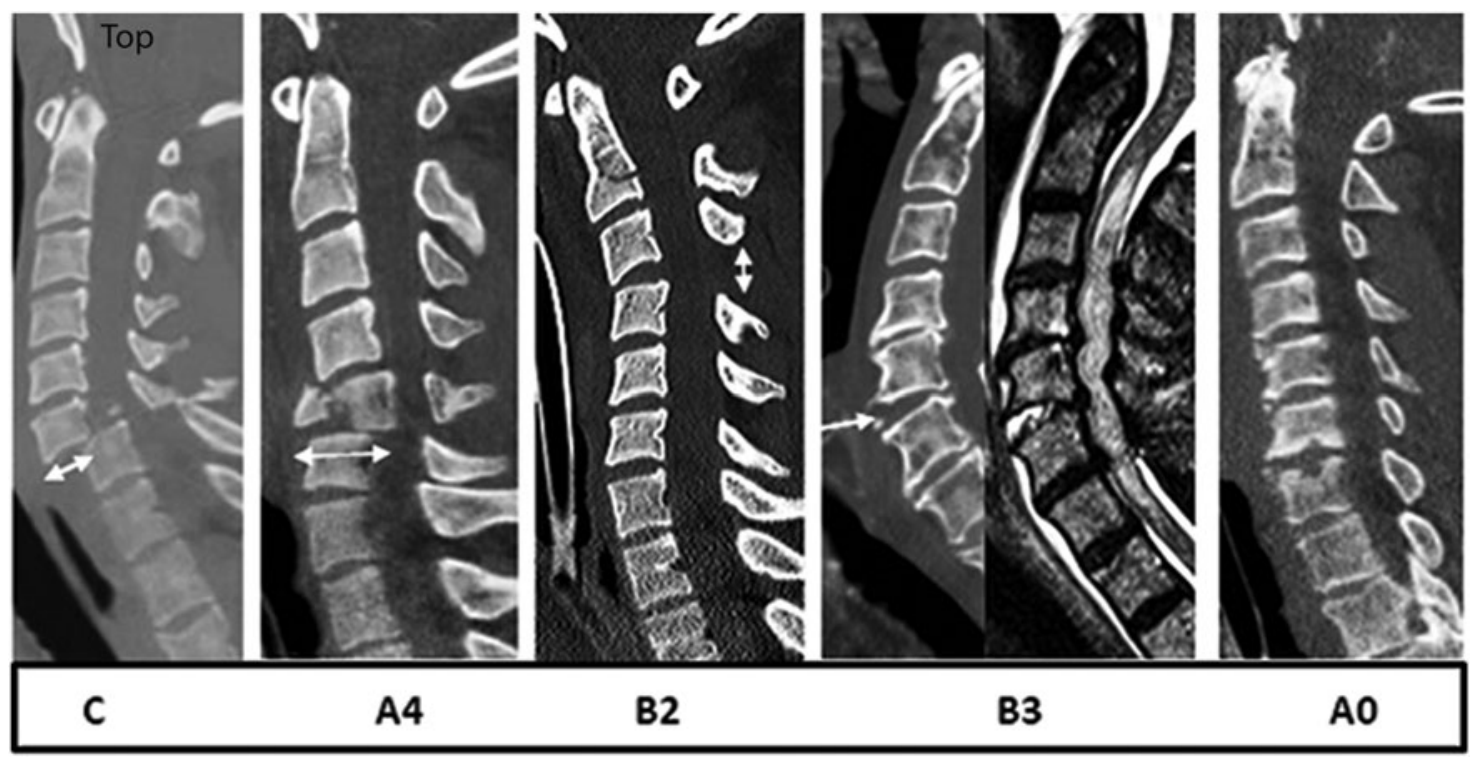

FIG. 3. Midsagittal subaxial CT and MRI cuts indicating morphology according to AOSpine Subaxial Cervical Spine Classification System. ${ }^{34} \mathrm{C}$, translation rotation and highly unstable injuries; A4, compression burst fractures; B2, flexion distraction without translation; B3, extension distraction without translation; A0, no imaging evidence of fracture dislocation.
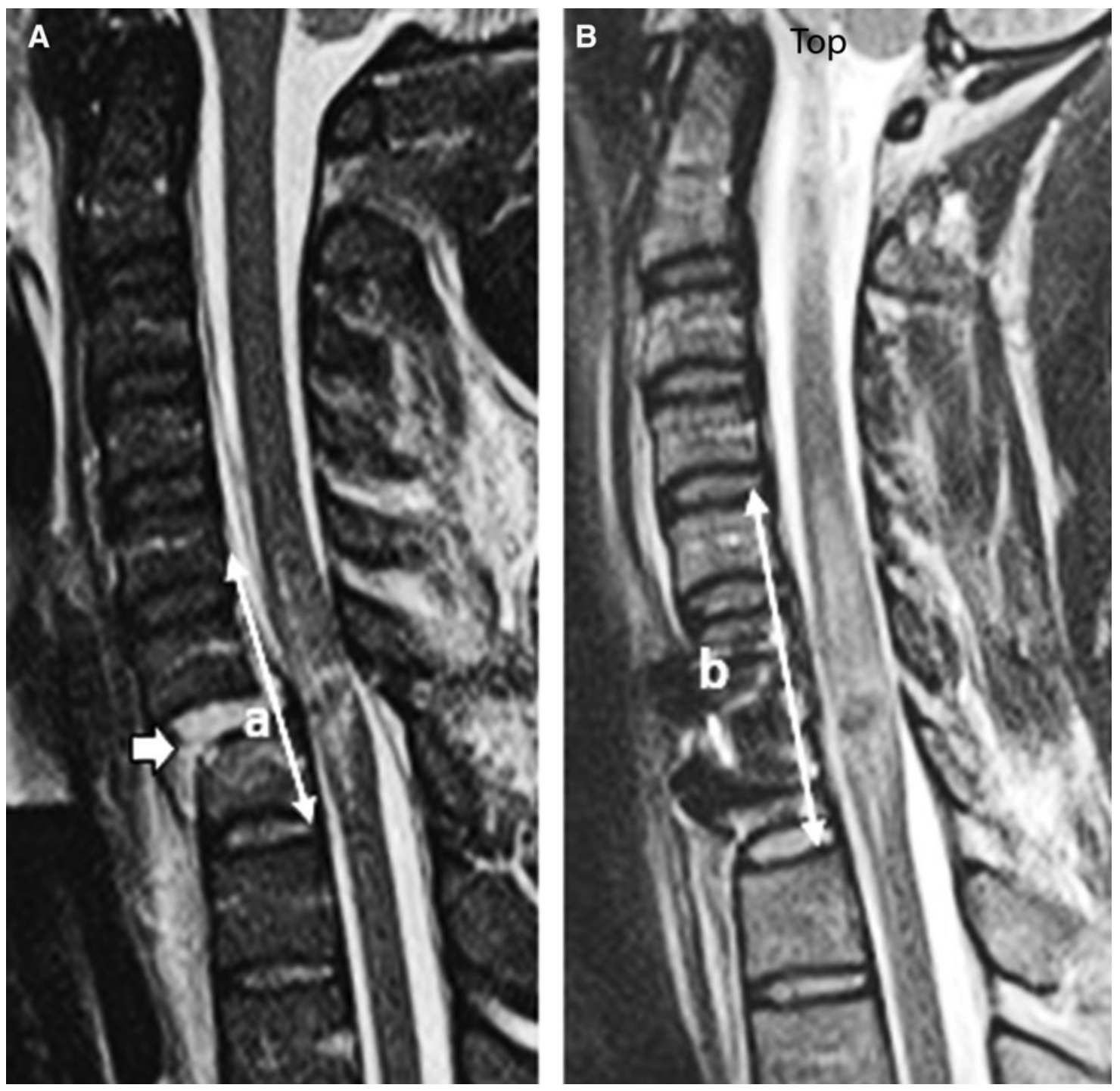

FIG. 4. Pre-operative (A) and post-operative (B) midsagittal magnetic resonance images indicating measured intramedullary lesion length $a$ and $b$. 

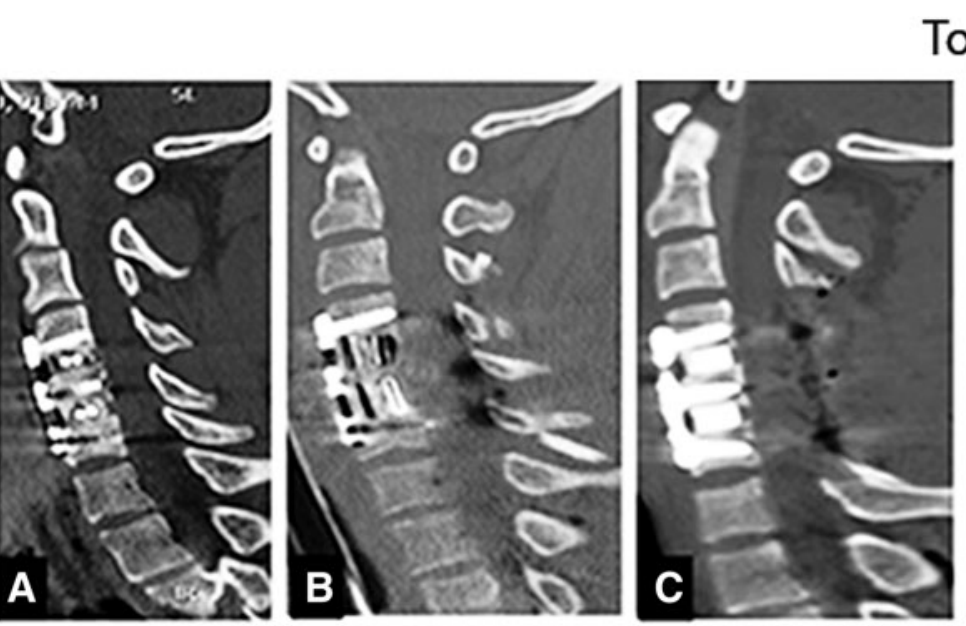

Top
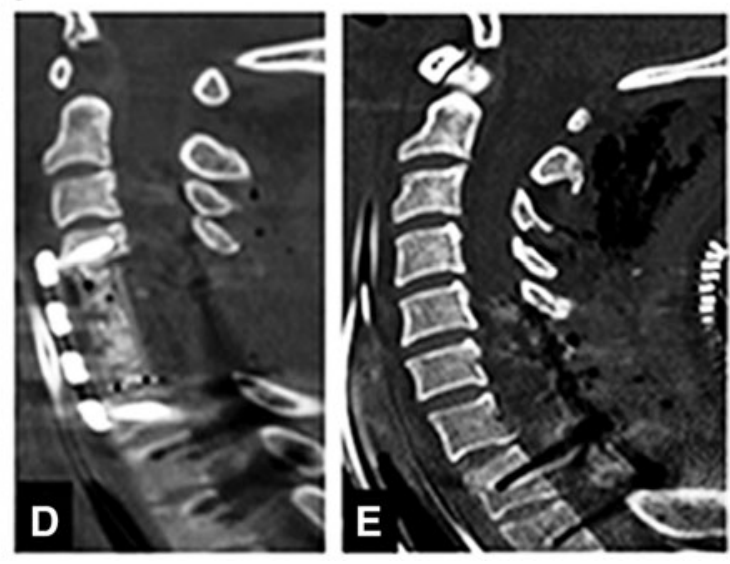

FIG. 5. Midsagittal CT scan of cervical spine indicating (A) anterior cervical discectomy and fusion (ACDF); (B) anterior cervical corpectomy and fusion (ACCF); (C) Combined ACDF and three level laminectomy and posterior spinal fusion (PSF); (D) ACCF (two levels) and Laminectomy (two levels) and PSF; and (E) three levels of laminectomy and PSF.

analysis were chosen after stepwise selection using Bayesian Information Criteria (BIC) to measure the efficiency of the parameterized model in terms of predicting data. ${ }^{44}$ Multiple effect modification terms were assessed, but no evidence of statistical interaction was detected. A final model was chosen based on the model with the smallest BIC value. Regression diagnostics were performed, consisting of Pearson chi-squared goodness-to-fit testing, tests for collinearity and specification, and examination of Pearson residual plots for influential observations. A $p$ value of $<0.05$ was considered statistically significant, and all tests were two-tailed. All analyses were performed in Stata/SE version 15.1 (Stata Corp, College Station, TX) and GraphPad Prism version 7.0d (GraphPad Software, La Jolla, CA).

\section{Results}

We examined 13 variables to assess whether they could in isolation or in regression models influence the achievement of successful decompression of a severely contused and swollen spinal cord across multiple motion segments (Table 1).

\section{Demographics and injury mechanisms}

Although patients who had complete decompression were about 5 years older than patients who were not successfully decompressed, this age difference did not reach statistical significance. Neither was the patient's sex found to influence the success of decompression $(p=0.55)$. Three well-known mechanisms of injury-motor vehicle accidents, mechanical falls, and sport injuries - did not affect decompression $(p=0.69)$

\section{Time interval from injury to admission, imaging studies, and decompression}

The mean time interval from injury to admission to the TRU in the decompressed patients was $2.7 \pm 4.3 \mathrm{~h}$ compared with $3.1 \pm$ $6.7 \mathrm{~h}$ in patients with unsuccessful decompression ( $p=$ not significant [NS]). The time interval from injury to CT scan between the two groups $(4.1 \pm 7.0$ and $4.2 \pm 6.9 \mathrm{~h})$ did not yield a significant influence on successful decompression. Similarly, the time interval from trauma to pre-operative MRI in the successfully decompressed patients was $8.3 \pm 7.7 \mathrm{~h}$, and in the group whose decompression failed it was $8.6 \pm 8.7 \mathrm{~h}(p=\mathrm{NS})$. The time from injury to post-operative MRI in the decompressed group was $49.4 \pm 32.6 \mathrm{~h}$, and in the group with incomplete decompression it was $48.2 \pm$ $30.0 \mathrm{~h}(p=\mathrm{NS})$. The median time to surgery in the patients who had successful decompression was $21.0 \pm 20.6 \mathrm{~h}$, and in the failed decompression group it was $22.8 \pm 21.5 \mathrm{~h}(p=0.56)$. In all, the measured time intervals were grossly similar and did not influence the achievement of successful spinal cord decompression as measured on post-operative MRI.

\section{Evidence of systemic injury severity}

At the time of arrival, the mean systolic blood pressure was $119 \mathrm{~mm} \mathrm{Hg}$ (median $118 \mathrm{~mm} \mathrm{Hg}$ ). Overall, in 17 patients the systolic blood pressure was $<90 \mathrm{~mm} \mathrm{Hg}$ before resuscitation. Systemic oxygenation $\left(\mathrm{SPO}_{2}\right)$ was unknown in 32 patients; however, in 152 patients, the mean $\mathrm{SPO}_{2}$ was $97 \%$ (median 98\%). Median GCS score was 15 . GCS score was $3-5$ in $10,6-8$ in five, $9-12$ in 28 , and $13-15$ in 141 . The mean ISS was 33.2 (median 26; range 1-75). Median ISS (interquartile range) in successfully decompressed patients was 26 , and in those with unsuccessful decompression it was $29(p=0.08)$.

\section{ASIA motor score and AIS grade}

On the ISNCSCI scale, the mean ASIA motor score in all patients was $13.6 \pm 12$ (median 10; range 0-50). ASIA motor score was unknown for one patient. ASIA motor score for the patients who had complete spinal cord decompression was $15.4 \pm 13.1$, and for patients with unsuccessful decompression it was $10.1 \pm 8.6$. This difference was statistically significant $(p<0.004)$. Additionally, AIS grade A patients were less likely to have successful decompression. The success of decompression in AIS grade A patients was $57.1 \%$, and in AIS grade B it was $81.5 \%(p<0.001)$.

\section{Normal anatomy of cervical spine}

Mean midsagittal diameter and the $\mathrm{C} 2-\mathrm{T} 1$ height of the subaxial cervical spine were not significantly different between the two groups ( $p=0.40$ and $p=0.10$, respectively; Table 1 ). 
Table 1. Unadjusted Outcomes, Stratified by Covariates, INCLUDING TYPE OF OPERATION $(\mathrm{N}=184)$

\begin{tabular}{|c|c|c|c|}
\hline Variable & $\begin{array}{l}\text { Decompressed } \\
(\%)\end{array}$ & $\begin{array}{c}\text { Not } \\
\text { decompressed } \\
(\%)\end{array}$ & $\begin{array}{c}p \\
\text { value }\end{array}$ \\
\hline Mean age (SD) & $45.1(19.1)$ & $40.3(18.1)$ & 0.10 \\
\hline Sex (\% in each group) & & & 0.55 \\
\hline Male & $96(64.4)$ & $53(35.6)$ & \\
\hline Female & $25(71.4)$ & $10(15.9)$ & \\
\hline $\begin{array}{l}\text { Mechanisms of injury } \\
(\% \text { total in each group) }\end{array}$ & & & 0.69 \\
\hline Motor vehicle crash & $40(33.1)$ & $29(46)$ & \\
\hline Fall & $55(45.5)$ & $17(27)$ & \\
\hline Sports accident & 19 (15.7) & $12(19.1)$ & \\
\hline Other & $7(5.8)$ & $5(7.9)$ & \\
\hline $\begin{array}{l}\text { Median Injury Severity } \\
\text { Score (IQR) }\end{array}$ & $26(21,35)$ & $29(25,50)$ & 0.08 \\
\hline $\begin{array}{l}\text { Mean ASIA motor } \\
\text { score (SD) }\end{array}$ & $15.4(13.1)$ & $10.1(8.6)$ & 0.004 \\
\hline $\begin{array}{l}\text { ASIA impairment scale } \\
(\% \text { total in each group })\end{array}$ & & & 0.001 \\
\hline A & $68(57.1)$ & $51(42.9)$ & \\
\hline B & $53(81.5)$ & $12(10.1)$ & \\
\hline $\begin{array}{l}\text { Mean cervical canal } \\
\text { diameter in mm (SD) }\end{array}$ & $12.5(1.5)$ & $12.3(1.4)$ & 0.40 \\
\hline $\begin{array}{l}\text { Mean cervical vertebral } \\
\text { height in mm (SD) }\end{array}$ & $93.6(7.7)$ & $95.5(7.2)$ & 0.10 \\
\hline Injury type (on $\mathrm{CT}, \%$ ) & & & 0.68 \\
\hline Translation rotation $(\mathrm{C})$ & $42(61.7)$ & $26(38.2)$ & \\
\hline $\begin{array}{l}\text { Burst/Compression } \\
\text { fracture (A3 and A4) }\end{array}$ & $28(68.3)$ & $13(31.7)$ & \\
\hline $\begin{array}{l}\text { No fracture/dislocation } \\
\text { (A0) }\end{array}$ & $29(74.4)$ & $10(25.6)$ & \\
\hline $\begin{array}{l}\text { Distraction injury } \\
\text { (B2 and B3) }\end{array}$ & $16(61.5)$ & $10(38.5)$ & \\
\hline Other & $6(60)$ & $4(40)$ & \\
\hline $\begin{array}{l}\text { Median hours to } \\
\text { operation (IQR) }\end{array}$ & $20.9(20.6)$ & $22.8(21.5)$ & 0.56 \\
\hline Surgical procedure & & & 0.004 \\
\hline Discectomy & $22(46.8)$ & $25(53.2)$ & \\
\hline Corpectomy & 17 (58.6) & $12(41.4)$ & \\
\hline $\begin{array}{r}\text { Discectomy and } \\
\text { laminectomy }\end{array}$ & $38(71.7)$ & $15(28.3)$ & \\
\hline $\begin{array}{c}\text { Corpectomy and } \\
\text { laminectomy }\end{array}$ & $19(73.1)$ & 7 (26.9) & \\
\hline Laminectomy only & $25(86.2)$ & $4(13.8)$ & \\
\hline $\begin{array}{l}\text { Mean pre-operative } \\
\text { IMLL in mm (SD) }\end{array}$ & $43.5(15.3)$ & $55.8(18)$ & $<0.0001$ \\
\hline $\begin{array}{l}\text { Mean post-operative } \\
\text { IMLL in } \mathrm{mm}(\mathrm{SD})\end{array}$ & $62.4(26)$ & $87.7(36)$ & $<0.0001$ \\
\hline Laminectomy (\%) & $39(51.3)$ & 37 (48.7) & $<0.001$ \\
\hline
\end{tabular}

$\mathrm{SD}$, standard deviation; IQR, interquartile range; CT, computed tomography; IMLL, intramedullary lesion length.

\section{Injury morphology}

We compared the AOSpine subaxial cervical spine classifica$\operatorname{tion}^{34}$ subtypes between the two groups, but found no statistically significant difference between the morphology patterns of successfully and unsuccessfully decompressed patients (Table $1 ; p=0.68$ ).

\section{Surgical technique}

To better clarify the operative approaches chosen by the 14 neurosurgeons, we cross-tabulated morphology (Fig. 3) and surgical technique (Fig. 5). Most of the 68 patients with translation rotation injuries (e.g., facet locks,45 AOSpine type $\mathrm{C}^{41}$ ) were managed by either ACDF alone or ACDF with laminectomy and posterior spinal fusion (PSF; 78\%). Injuries to the vertebral body such as burst or compression fractures ${ }^{45}$ (AOSpine types A3 and A4) ${ }^{41}$ were approached by either ACCF or ACCF and laminectomy and PSF $(95.2 \%)$. Almost half of the 39 patients with no visible fracture dislocation (AOSpine type A0) ${ }^{41}$ had stand-alone laminectomy and PSF $(48.7 \%)$ or ACDF with or without laminectomy and PSF $(41 \%)$. Twenty-six patients had distraction injuries ${ }^{46}$ without translation (AOSpine types B2 or B3). ${ }^{41}$ From this group $84.6 \%$ were managed with either ACDF alone or ACDF with laminectomy with or without PSF. These surgical techniques were compatible with the recommendations depicted in the management algorithm of Dvorak and colleague, ${ }^{27}$ and the techniques used by Vale and colleagues ${ }^{10}$ and Vaccaro and colleagues ${ }^{9}$ (Table 2).

Our study indicated that adding laminectomy to ACDF, ACCF, or stand-alone laminectomy increased the probability of decompression. Additionally, as the number of levels of laminectomy increased from one to five, regardless of the anterior approach chosen, the rate of decompression increased proportionally (Fig. 6).

\section{ACDF only}

Forty-seven of 184 (25.5\%) patients had a mean age of 45.0 years and underwent ACDF as their primary surgical approach without laminectomy (Fig. 7). The mean time to surgery was $17.3 \mathrm{~h}$ following trauma. In 35 patients, only one skeletal segment was fused. Twolevel ACDF was undertaken in nine patients and three-level surgery was employed in three patients. The injury morphology in 36 of 47 (77\%) patients was either translation rotation or distraction. The mean ASIA motor score in these patients was 14.7 and AIS grade was A in 33 (70\%). IMLL was 45.0 millimeters in the pre-operative MRI and 68.7 millimeters in the post-operative MRI (NS, from the entire cohort IMLL measurements). Only 22 of 47 patients (46.8\%) in this group of patients had successful decompression of the spinal cord. Five patients $(10.6 \%)$ died in this series. The mean hospital length of stay was 23.2 days.

Table 2. Cross-Tabulation of Injury Morphology and Surgical Technique

\begin{tabular}{lcccccc}
\hline Morphology & $A C D F$ & ACCF & ACDF+Laminectomy & ACCF+Laminectomy & Laminectomy & Total \\
\hline Translation rotation (Type C) & $25(36.8)$ & $3(4.4)$ & $28(41.2)$ & $9(13.2)$ & $3(4.4)$ & $68(37)$ \\
Burst/ compression & $0(0)$ & $22(53.7)$ & $1(2.4)$ & $17(41.5)$ & $1(2.4)$ & $41(22.3)$ \\
A3+A4 (Type A) & $8(20.5)$ & $3(7.7)$ & $8(20.5)$ & $1(2.6)$ & $19(48.7)$ & $39(21.2)$ \\
No visible injury (A0) & $11(42.3)$ & $0(0)$ & $11(42.3)$ & $0(0)$ & $4(15.4)$ & $26(14.1)$ \\
Distraction (Types B2 and B3) & $3(30)$ & $1(10)$ & $3(30)$ & $1(10)$ & $2(20)$ & $10(5.4)$ \\
Other & $47(25.5)$ & $29(15.8)$ & $51(27.7)$ & $28(15.2)$ & $29(15.8)$ & $184(100)$ \\
Total &
\end{tabular}

$\mathrm{ACDF}$, anterior cervical discectomy and fusion; ACCF, anterior cervical corpectomy and fusion. 


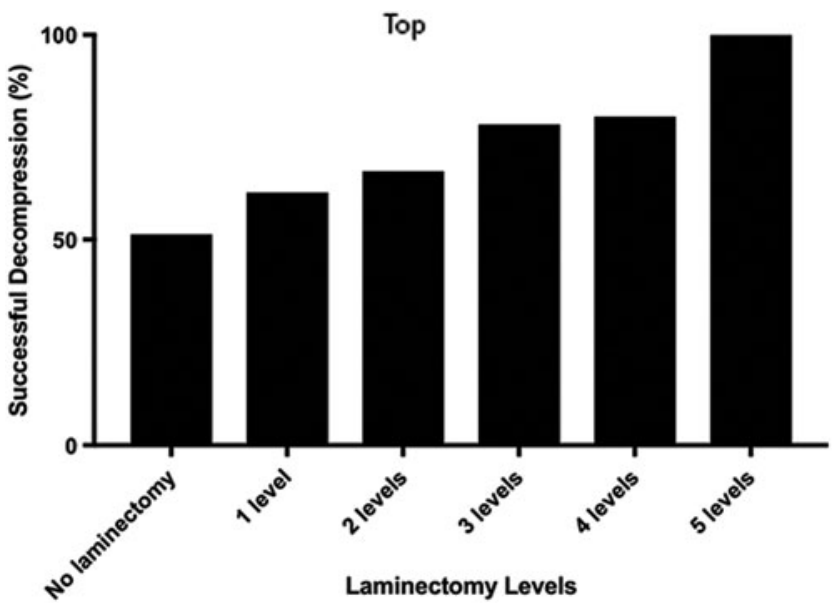

FIG. 6. Graph indicating progressively increased chances of success in decompression as the levels of laminectomy increase with surgical technique.

\section{Corpectomy (ACCF) only}

Twenty-nine of $184(15.7 \%)$ patients with a mean age of 29.3 years had corpectomy at one level (28 patients) or two levels (one patient) without laminectomy (Fig. 8). The mean time to surgery following injury was $24.8 \mathrm{~h}$. Mean ASIA motor score in this group was 17.8. The AIS grade was A in 15 (50.7\%) and B in 14 patients. Twenty-two of $29(75.6 \%)$ patients had burst or compression fractures (A3 or A4). IMLL was 45.8 millimeters in the preoperative MRI and 67.9 millimeters in the post-operative MRI. The hospital length of stay in this group was 20.3 days, and two patients died. Seventeen of $29(58.6 \%)$ patients had complete spinal cord decompression (Fig. 8).

\section{ACDF followed by laminectomy}

Fifty-three of 184 (28.8\%) patients with a mean age of 47.1 years underwent ACDF followed by laminectomy (Fig. 9). The mean ASIA motor score was 11.9 , and the mean time to surgery was $20.1 \mathrm{~h}$ following trauma. The injury morphology in this group of patients was translation rotation in 30 and distraction in 11. Of the 53 patients, 34 (53\%) underwent one-level ACDF, 13 underwent two-level, five underwent three-level, and one patient underwent four-level ACDF. Laminectomy was one-level in eight, two-level in 15 , three-level in 15 , four-level in 11 , and five-level in four patients. Thirty-eight of $53(71.7 \%)$ patients had complete spinal cord decompression. IMLL was 47.2 and 73.4 millimeters in the pre-operative and post-operative MRI studies, respectively. Six patients $(11.3 \%)$ died in this series. The mean hospital length of stay was 28 days.

\section{ACCF followed by laminectomy}

Twenty-six patients underwent corpectomy with one to five levels of laminectomy (Fig. 10). The mean time to surgery following trauma was $19.7 \mathrm{~h}$ in this cohort. Laminectomy was onelevel in five patients, two-level in nine, three-level in nine, four-
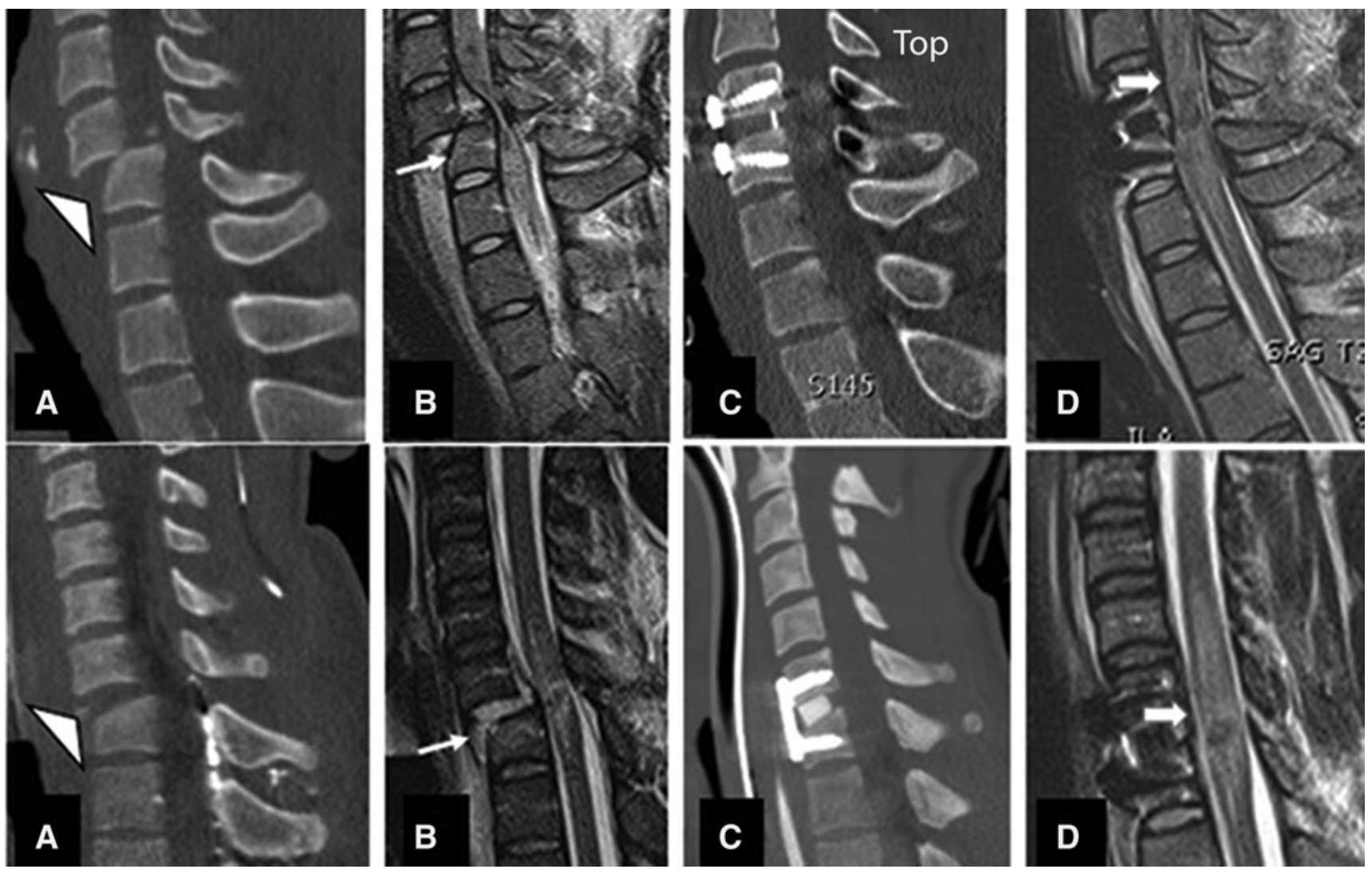

FIG. 7. Midsagittal CT and MRI images of two subaxial cervical spine injuries without (upper rows) and with (lower rows) success in decompression. In the upper row a translation rotation injury (A and $\mathbf{B}$, arrowhead and arrow, respectively) was managed with a singlelevel ACDF, while the lower row indicates another translation rotation and compression fracture (A and B) managed with a single-level of anterior cervical discectomy and fusion (C) and successful decompression (arrow). 

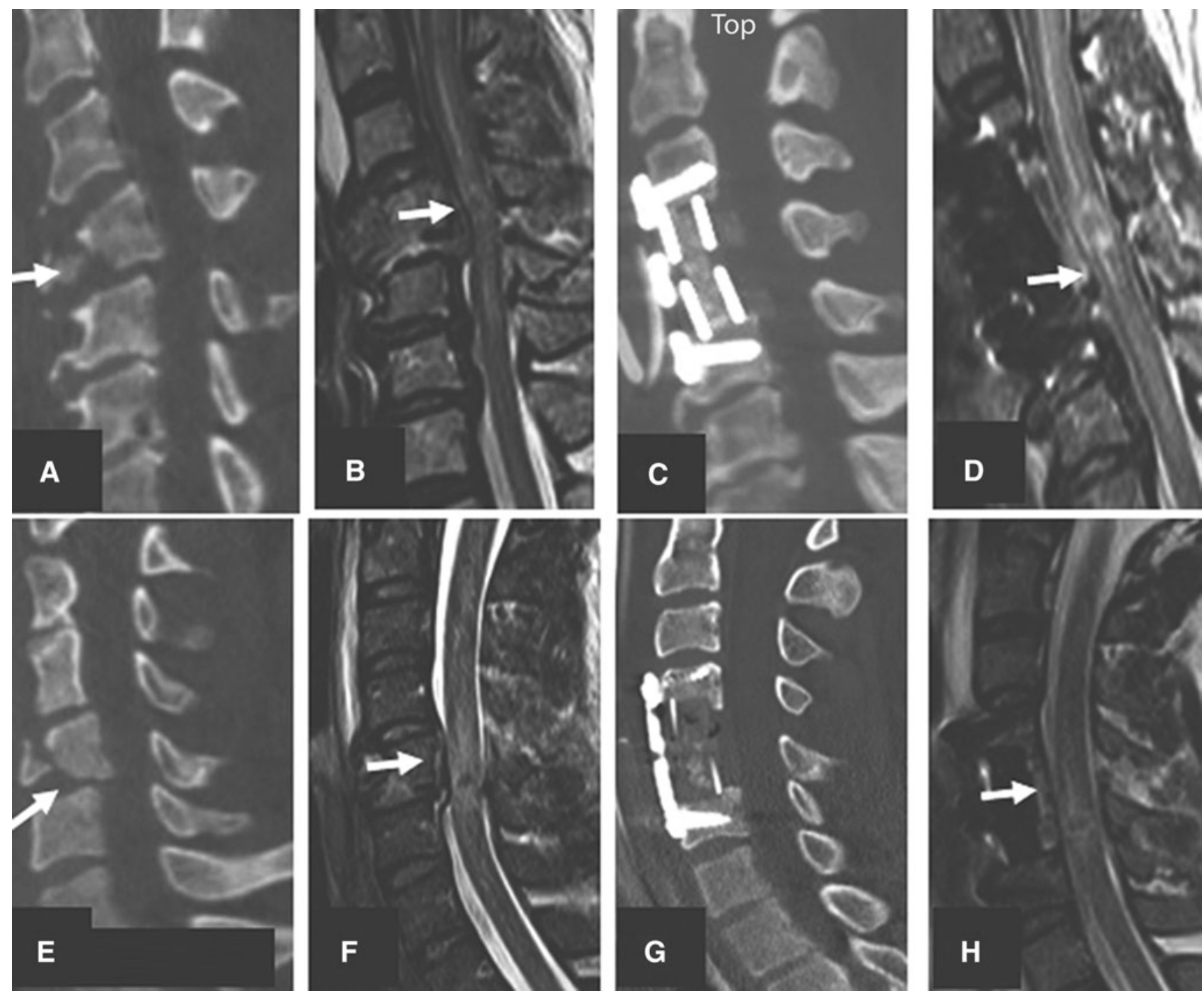

FIG. 8. Midsagittal CT and MRI of one level ACCF with and without success in decompression. (A-D) indicate a teardrop fracture (A and $\mathrm{B}$ arrows) indicating compressed spinal cord at $\mathrm{C} 4$ and beyond. (C) and (D) show one level corpectomy with no evidence of decompression (D). (E) and (F) indicate a C5 tear drop fracture managed with corpectomy and successful decompression of spinal cord ( $\mathbf{G}$ and $\mathbf{H}$ arrows).

level in two, and five-level in one. The mean age of this group was 31.9 years. SCI was complete in 16 patients. These patients had a mean AISA motor score of 12. The injury morphology was burst/ compression or translation rotation in $65.4 \%$. Nineteen patients $(73 \%)$ in this group had complete decompression of SCI following surgery. Mean IMLL was 54.3 and 80.6 millimeters in the pre-operative and post-operative MRI studies, respectively. None of these 26 patients died. The mean hospital length of stay was 22.9 days.

\section{Laminectomy only}

Twenty-nine motor complete patients underwent laminectomies between two- and five-levels (Fig. 11). The mean time to surgery following trauma was $28.2 \mathrm{~h}$. Laminectomy was two-levels in one patient, three-level in eight patients, four-level in seven patients, and five-level in eight patients. Nineteen of $29(65.5 \%)$ patients in this series had no visible fracture dislocations. AIS grade was almost equally divided between the A (15 patients) and B (14 patients) groups. The mean ASIA motor score was 12. The measured IMLL was 49 and 65.3 millimeters in the pre-operative and post-operative
MRI studies, respectively. Two patients died in this series. The mean length of hospital stay was 23.8 days. Twenty-five of 29 patients $(86.2 \%)$ in this cohort had complete spinal cord decompression. Laminectomy in 22 patients was in conjunction with internal fixation. Seven of 29 patients with stand-alone laminectomy did not have posterior spinal fusion. Morphology in all these seven patients was A0 with no evidence of fracture dislocations. Laminectomy was at two levels in two, three levels in three, and four levels in two patients. Decompression was successful in all seven patients.

\section{Intramedullary lesion length}

Patients with shorter measured IMLL on the pre-operative or post-operative MRI imaging studies were significantly more likely to be completely decompressed $(p<0.0001$; Table 1$)$.

\section{Analysis of all five surgical techniques together}

Comparison of all of the above-mentioned surgical techniques showed that those employing stand-alone laminectomy or 

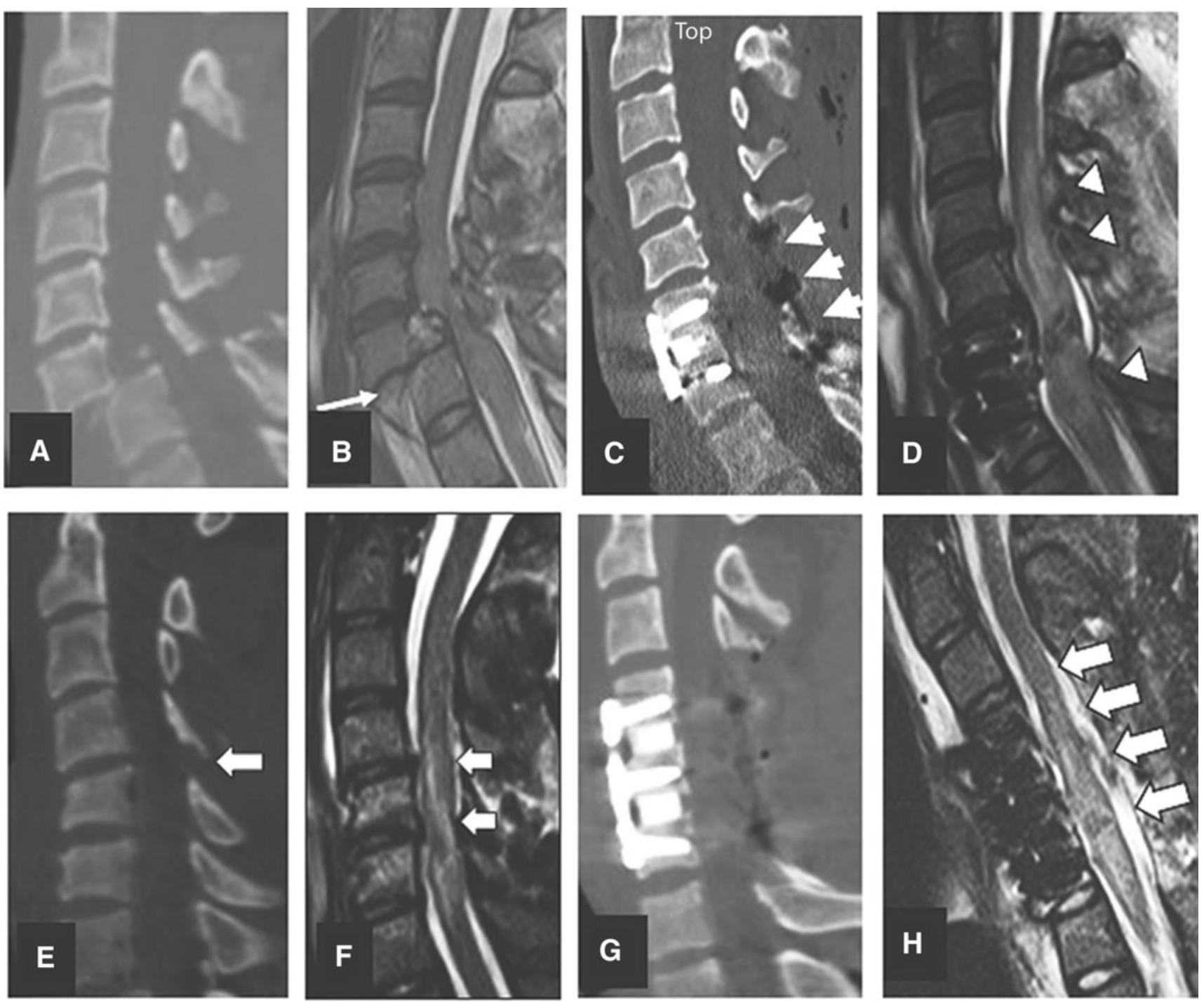

FIG. 9. Midsagittal CT and MRI images belonging to two different patients managed by anterior cervical discectomy and fusion (ACDF) and laminectomy. Upper row indicates a C6/C7 translation rotation injury (A and B) with evidence of spinal cord compression. (C) and (D) show one level ACDF and two levels of laminectomy with inadequate decompression of the spinal cord at C4 and C5 and C7. (E-H) indicate a flexion compression injury and evidence of spinal cord compression at C5 and C6 segments. The patient had ACDF at C5/6 and C6/7 with three levels of laminectomy and posterior spinal fusion $(\mathbf{G}$ and $\mathbf{H}$ ) with adequate decompression of the spinal cord (arrows).

laminectomy with or without PSF as a supplement to an anterior approach were more successful in achieving decompression of the spinal cord $(p<0.004$; Table 1).

\section{Multi-variate regression analysis}

Analysis of all the co-variates in multiple logistic regression models indicated that laminectomy was important for achieving successful decompression of the spinal cord (Table 3).

\section{Discussion}

Evidence from this clinical investigation indicates that in motor complete cervical TSCI patients, laminectomy increases the likelihood of complete decompression of the spinal cord. Notably, the rate of successful decompression increases with an increasing number of levels chosen for laminectomy.
Pre-clinical studies have indicated that TSCI leads to capillary disruption at the injury epicenter ${ }^{47-49}$ resulting in the extravasation of blood products within the central gray matter. ${ }^{48-53}$ This ischemia subsequently initiates a number of molecular cascades, ${ }^{54}$ resulting in the upregulation of certain ion channel receptors at the cell membrane, ${ }^{54,55}$ which culminates in the formation of cytotoxic edema and spinal cord swelling potentially well beyond the primary site of initial energy dispersion (Fig. 12) ${ }^{56}$ Spinal cord swelling thus spreads rostrally and caudally from the injury epicenter, leading to the obliteration of the surrounding SAS. The swollen spinal cord becomes compressed against the inelastic dura, and osseous-ligamentous structures of the spinal canal. ${ }^{28,38,39,57}$ In vivo imaging studies have confirmed that bleeding at the injury epicenter and spinal cord swelling are clearly visualized on T2WI and SWI sequences. ${ }^{58-61}$ In a rodent model of SCI, Bilgen and colleagues ${ }^{62}$ reported MRI spinal cord swelling within 10 min of trauma followed by the secondary spread of edema beyond the site of impact 

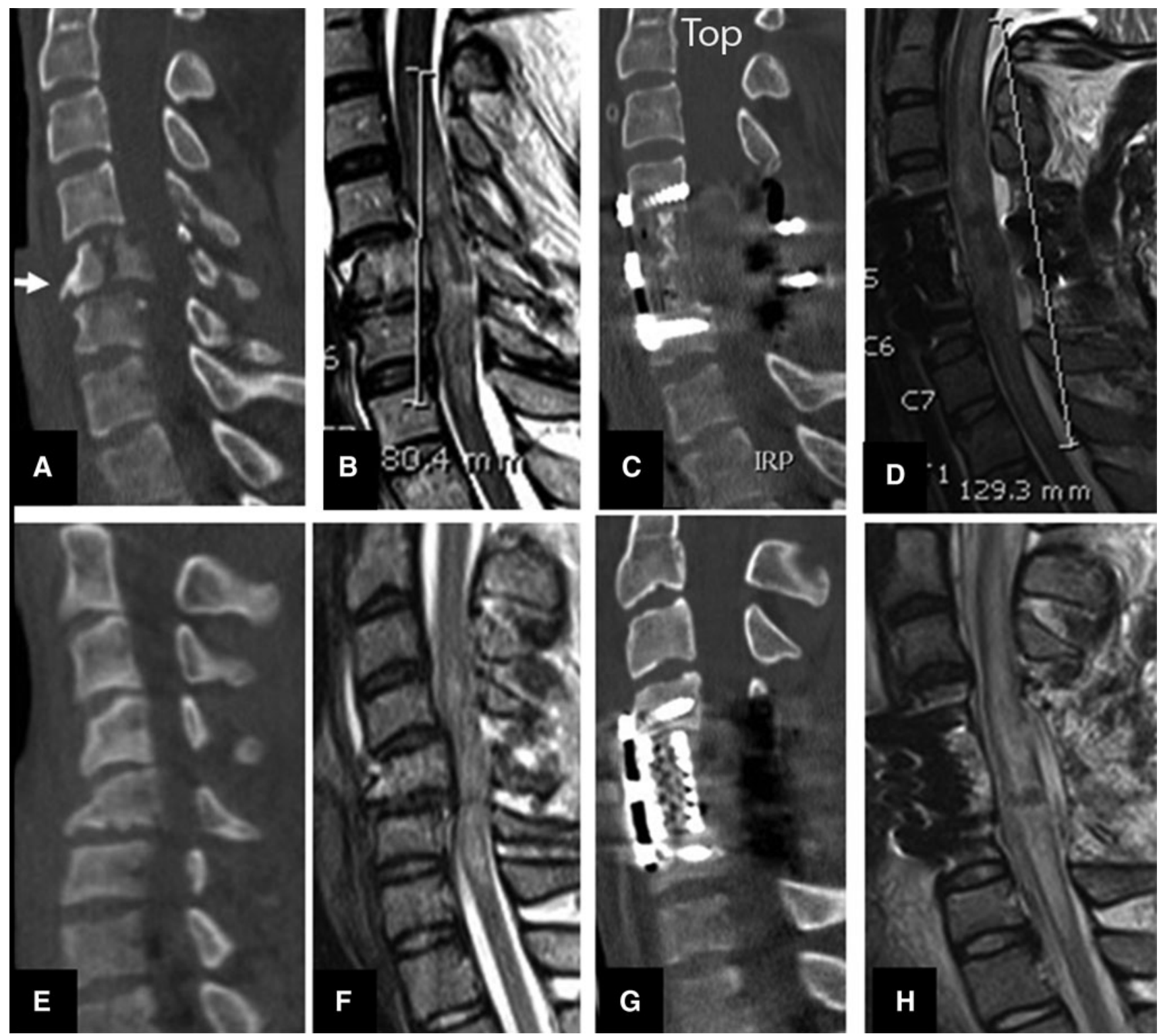

FIG. 10. Midsagittal CT and MRI images indicating wo vertical compression and teardrop fractures managed by corpectomy and laminectomy. Upper row plates (A-D) indicate C5 corpectomy and three-level laminectomies and posterior spinal fusion (PSF) with inadequate decompression at C3 and C7. Lower row (E-H) plates showing C5 corpectomy and three-level laminectomy and PSF with full decompression of the spinal cord.

on subsequently acquired imaging studies. In humans, Le and colleagues and Aarabi and colleagues reported an IMLL expansion rate of nearly $900 \mu$ meters/h when comparing pre-operative with post-operative MRI studies of patients with motor complete subaxial TSCI. ${ }^{38,39}$

The findings of the present study confirm the phenomenon of secondary spinal cord swelling over time following the initial trauma. IMLL, an indicator of longitudinal spinal cord swelling, measured an average of $47.7 \mathrm{~mm}$ on the initial pre-operative MRI studies of the patients in this cohort (mean time from injury, $8.4 \mathrm{~h}$ ). Comparatively, the mean IMLL was $71.1 \mathrm{~mm}$ on the post-operative MRI studies (mean time from injury, $48.9 \mathrm{~h}$ ), resulting in an overall $49 \%$ increase in lesion length. While the mean height of C2-T1 osseous-ligamentous motion segments was $94.3 \mathrm{~mm}$ (standard deviation $7.5 \mathrm{~mm}$ ), in 38 of $184(20.6 \%)$ patients the IMLL ranged from 94.3 to $191.8 \mathrm{~mm}$. One important implication of these findings is that the unchecked progression of secondary spinal cord swelling may extend beyond the subaxial cervical spine proper, toward the brainstem rostrally and caudally below $\mathrm{T} 1$, thereby increasing the morbidity and mortality of these patients.

Planning an appropriate operative intervention, which increases the likelihood of complete decompression of the spinal cord, becomes even more significant since decompression may significantly affect AIS grade conversion. In a recent investigation of 100 AIS grade A, B, and C patients with subaxial TSCI, a connection was found between the extent of spinal cord decompression and upward AIS grade conversion during a 6-month follow-up period. ${ }^{28}$ Upward AIS grade conversion was $58.9 \%$ in 73 patients with adequate decompression versus $18.5 \%$ in patients without adequate decompression $(p<0.001)$. The present study indicates that 

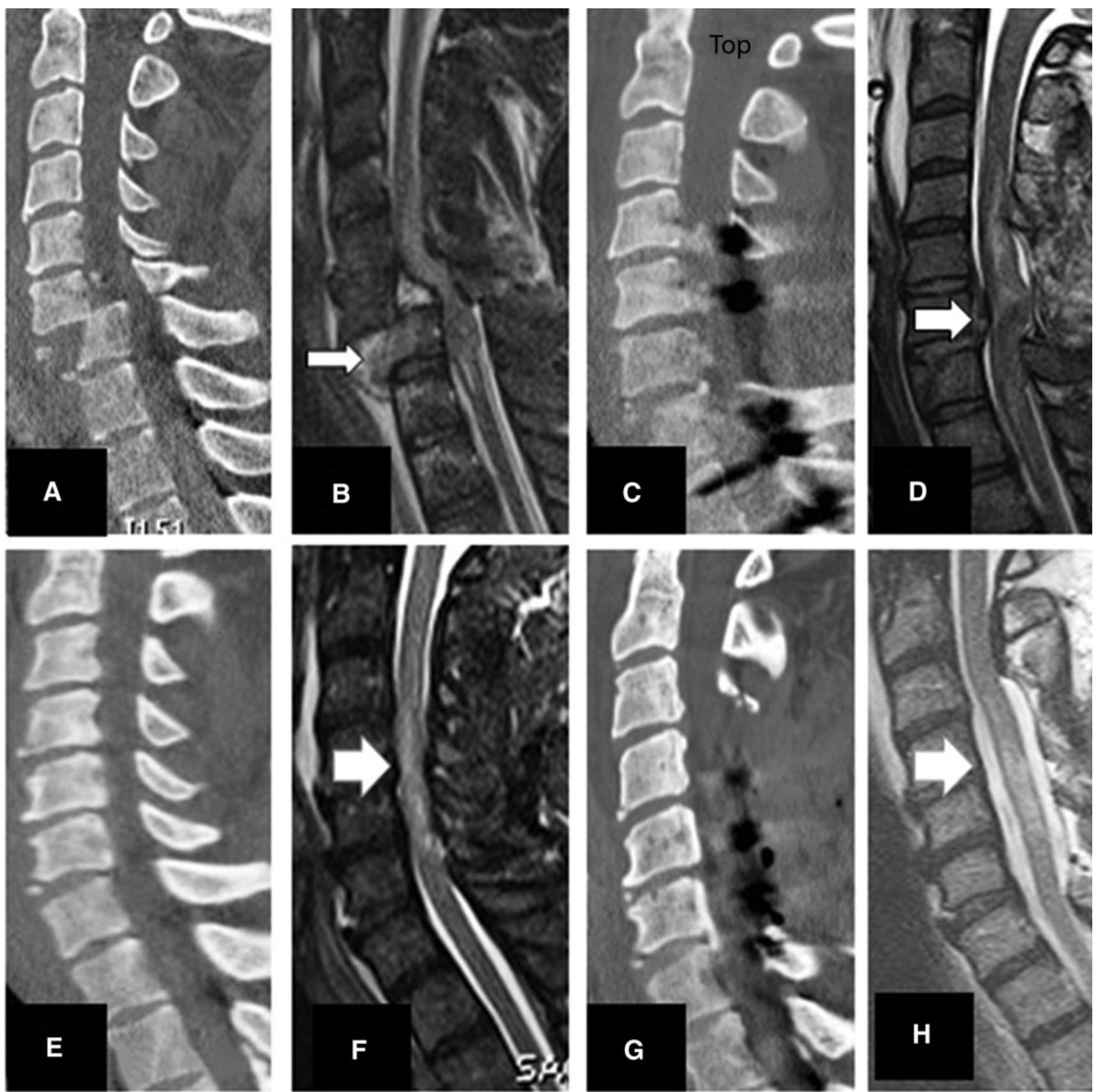

FIG. 11. Midsagittal views of two motor complete traumatic spinal cord injury patients with translation rotation (A-D) and no evidence of subaxial cervical spine fracture dislocations (E-H). Inadequate laminectomy and posterior spinal fusion (PSF) in the first patient did not decompress the cord adequately (at C7, plate D). Images in the lower row indicate that 4 level laminectomies and PSF completely decompressed the spinal cord.

laminectomy increases the probability of complete decompression (odds ratio 4.85; 95\% CI 2.2-10.6; $p<0.001$ ).

Recent therapeutic trials confirm the continued importance of present research on the combined effects of the timing of operative intervention and extent of surgical decompression of the traumatically injured cervical spinal cord. . $^{7,11,12,15,20,23-25,63-65}$ With this in mind, we argue that data collection, analysis, and reporting of results are potentially confounded in trials that neither follow a standardized algorithm for surgical intervention nor attend to the issue of spinal decompression and its post-operative confirmation. ${ }^{66-68}$

According to the most currently accepted management algorithms for managing subaxial TSCI, the presence of SCC at the time of initial radiographic assessment does factor into the decision of operative versus non-operative management. However, the choice of the operative technique itself (whether anterior or posterior or a combination and the rostral-caudal extent of intervention) has been primarily guided to date by the goal of correcting structural instability and misalignment. While our experience largely supports the evidence-based paradigm of Dvorak and colleagues, ${ }^{27}$ our research suggests that it may be necessary to supplement this currently accepted algorithm in order to more adequately address the relationship between the chosen operative approach, the extent of spinal cord decompression, and the re-establishment of structural stability and alignment. Nevertheless, as the preceding discussion 
Table 3. Multivariate Logistic Regression of Covariates $(\mathrm{N}=184)$

\begin{tabular}{|c|c|c|c|c|c|c|}
\hline Variable & $\begin{array}{l}\text { Unadjusted } \\
\text { odds ratio }\end{array}$ & $95 \% C I$ & $p$ value & $\begin{array}{l}\text { Adjusted } \\
\text { odds ratio }\end{array}$ & $95 \% C I$ & $p$ value \\
\hline Age & 1.01 & $0.99-1.03$ & 0.10 & 1.01 & $0.98-1.03$ & 0.12 \\
\hline Sex & 0.72 & $0.32,1.60$ & 0.42 & 0.80 & $0.30-2.13$ & 0.66 \\
\hline ISS & 0.99 & $0.97-1.001$ & 0.07 & 0.99 & $0.97-1.02$ & 0.65 \\
\hline Pre-operative IMLL (mm) & 0.96 & $0.94,0.98$ & $<0.001$ & 0.98 & $0.96-1.01$ & 0.18 \\
\hline Post-operative IMLL (mm) & 0.97 & $0.96,0.98$ & $<0.001$ & 0.98 & $0.96-1.00$ & 0.051 \\
\hline \multicolumn{7}{|l|}{ Injury type (on $\mathrm{CT}, \%$ ) } \\
\hline Fracture/dislocation & 1.61 & $0.99-2.6$ & 0.055 & Ref. & Ref. & Ref. \\
\hline Compression fracture & 1.33 & $0.58-3.03$ & 0.49 & 1.48 & $0.54-4.03$ & 0.44 \\
\hline No fracture/dislocation & 1.79 & $0.75-4.28$ & 0.19 & 0.83 & $0.28-2.4$ & 0.73 \\
\hline Distraction injury & 0.99 & $0.39-2.5$ & 0.98 & 0.37 & $0.11-1.29$ & 0.12 \\
\hline Other & 0.93 & $0.24-3.6$ & 0.92 & 0.63 & $0.13-3.01$ & 0.57 \\
\hline Laminectomy & 2.99 & $1.6-5.61$ & 0.001 & 4.85 & $2.2-10.6$ & $<0.001$ \\
\hline
\end{tabular}

CI, confidence interval; ISS, Injury Severity Score; IMLL, intramedullary lesion length.

shows, the time-dependent process of secondary spinal cord swelling has far-reaching consequences. As a result, surgical strategies must anticipate this phenomenon while addressing the issue of alignment/stability. The most effective strategy must not only follow the evidence-based algorithm of Dvorak and colleagues. ${ }^{27}$ we suggest, but also assure complete spinal cord decompression. With regard to the role of MRI, we suggest that the detection of SCC on admission studies should influence not only the decision to operate but also, in conjunction with admission neurologic status (i.e., AIS grade), the choice of a specific surgical strategy. In this work, we show that the incorporation of laminectomy into the overall surgical strategy is more likely to yield optimal decompressive outcomes.

Laminectomy, we realize, may also have its limitations for decompressing the injured cervical spinal cord. In our investigation, standard anatomical alignment and decompression re-established a patent SAS in $121(66 \%)$ patients; however, in seven (11\%) of 63 patients who had failed decompression, even laminectomy was insufficient for re-establishing patency of the SAS against a nonstretchable dura mater. These patients could have benefited from expansive duraplasty (Fig. 13). Here, there is an analogy to be made with the traumatically injured brain, where expansile duraplasty is almost invariably carried out as part of decompressive craniectomy. Similar to the pathophysiological principles of diffuse traumatic brain injury ${ }^{69-72}$ and the Monro-Kellie Doctrine, ${ }^{73-75}$ it has been shown that increased intraspinal pressure (ISP) results in reduced spinal cord perfusion pressure, as well as changes in the pressure reactivity index ( $\mathrm{SPRX}$ ) and therefore spinal cord autoregulation. In 2015, Phang and colleagues ${ }^{65}$ recorded subdural ISP in patients with severe TSCI and showed that the ISP at the injury epicenter was nearly $10 \mathrm{~mm} \mathrm{Hg}$ higher than the ISP above or below the level of injury. Of significance was that the subdural ISP was comparable to intraparenchymal ISP at the injury epicenter, consistent with severe spinal cord compression within the region of interest. In a subsequent prospective comparative investigation of 21 patients (11 with laminectomy compared with 10 patients with laminectomy and duraplasty), the investigators ${ }^{76}$ reported improved ISP, spinal cord perfusion pressure (SCPP), and sPRx following expansive duraplasty. This investigation indicates that in a select group of patients, even laminectomy may not sufficiently improve ISP and sPRx, and

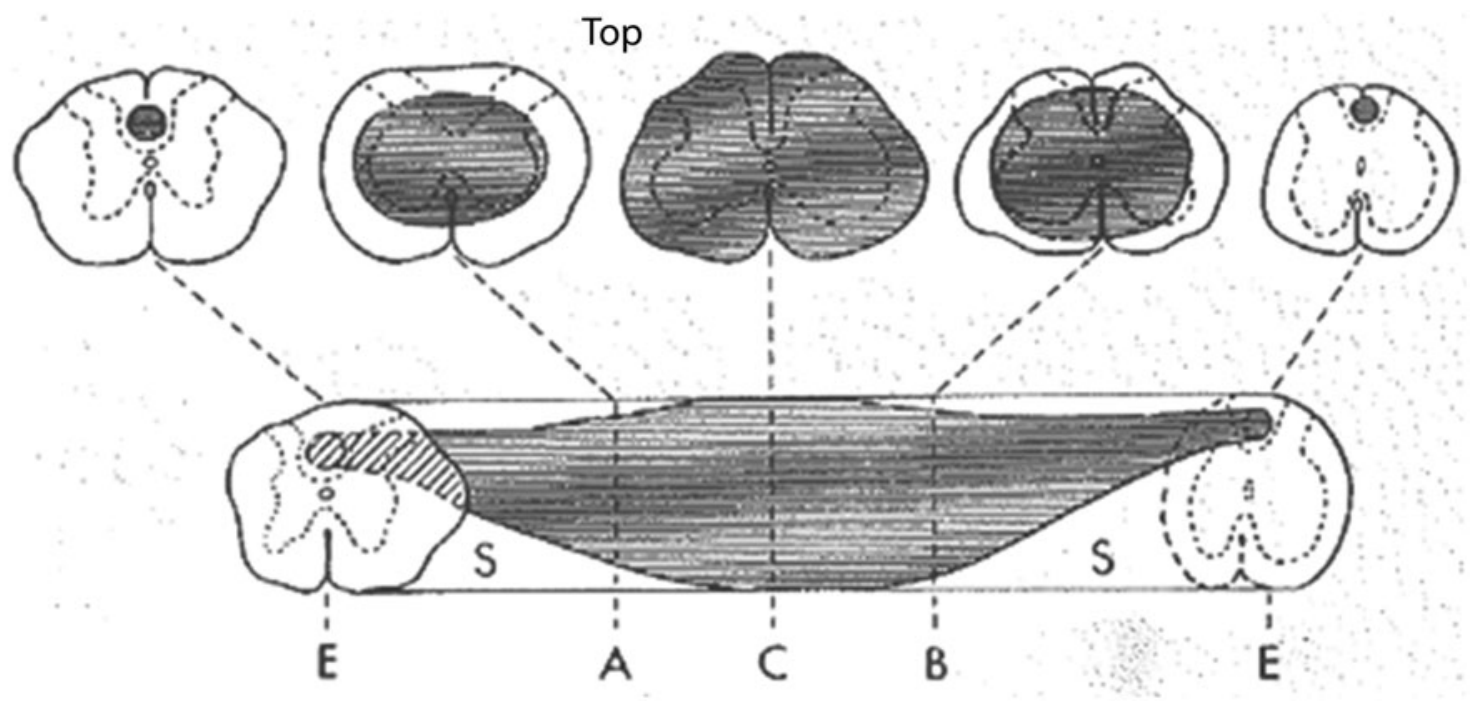

FIG. 12. Pre-clinical rodent model of experimental traumatic spinal cord injury indicating an ischemic necrotic spinal cord injury with rostral and caudal expansion over time. From Balentine, ${ }^{56}$ with permission. 

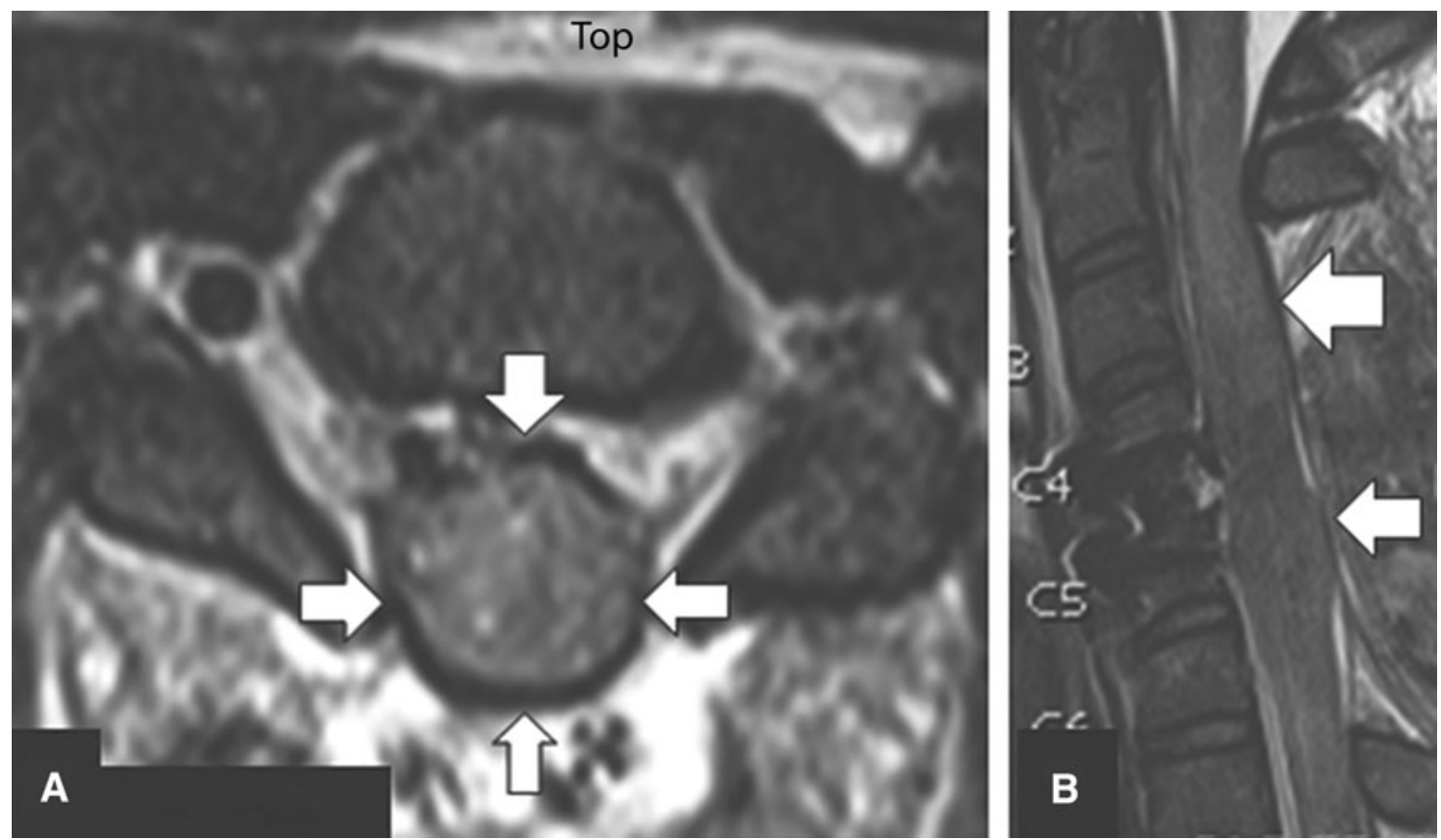

FIG. 13. Post-operative axial (A) and midsagittal (B) MRI images of a motor complete traumatic spinal cord injury indicating severe spinal cord swelling with no visualization of subarachnoid space in the region of laminectomy from C3-C6 (arrows).

surgeons may have to perform duraplasty, as is practiced in decompressive craniectomy for diffuse traumatic brain injury. ${ }^{77-80} \mathrm{In}$ conclusion, we suggest that within the presently evolving paradigm, further research is required to predict not only which patients will benefit from supplemental or stand-alone laminectomy but also those who will also require duraplasty to adequately decompress the injured cervical spinal cord.

Finally, we acknowledge that this report has inherent weaknesses, as it is not exempt from the potential influence of selection bias. It is a single institution trial, and although we collected the clinical and imaging data prospectively, analysis of the collected data was retrospective in nature.

\section{Summary}

The importance of timely and complete decompression of the contused and compressed spinal cord is gaining wider recognition among neurosurgeons and orthopedic surgeons as evidence increasingly supports its role as a neuroprotective surgical strategy. Nevertheless, the definition of "decompression" still remains heterogeneous and decompression has not been established according to evidence-based guidelines. This study highlights the significance of laminectomy as a supplemental or stand-alone procedure for achieving complete spinal cord decompression.

\section{Acknowledgment}

We appreciate the editorial work of Dr. Patricia A. Stephens.

\section{Author Disclosure Statement}

No competing financial interests exist.

\section{References}

1. Fehlings, M.G. (2009). The impact of continued cord compression following traumatic spinal cord injury. J. Neurosurg. Spine 11, $568-569$.
2. Carlson, G.D., Gordon, C.D., Oliff, H.S., Pillai, J.J., and Lamanna, J.C. (2003). Sustained spinal cord compression: part I: time-dependent effect on long-term pathophysiology. J. Bone Jt. Surg. Am. 85-A, 86-94.

3. Kobrine, A.I., Evans, D.E., and Rizzoli, H. (1978). Correlation of spinal cord blood flow and function in experimental compression. Surg. Neurol. 10, 54-59.

4. Kobrine, A.I., Evans, D.E., and V., R.H. (1979). Experimental acute balloon compression of the spinal cord. Factors affecting disappearance and return of the spinal evoked response. J. Neurosurg. 51, 841845.

5. Tarlov, I.M. and Herz, E. (1954). Spinal cord compression studies. IV. Outlook with complete paralysis in man. AMA Arch. Neurol. Psychiatry $72,43-59$

6. Tarlov, I.M. and Klinger, H. (1954). Spinal cord compression studies. II. Time limits for recovery after acute compression in dogs. AMA Arch. Neurol. Psychiatry 71, 271-290.

7. Papadopoulos, S.M., Selden, N.R., Quint, D.J., Patel, N., Gillespie, B., and Grube, S. (2002). Immediate spinal cord decompression for cervical spinal cord injury: feasibility and outcome. J. Trauma 52, 323-332

8. Fehlings, M.G., Vaccaro, A., Wilson, J.R., Singh, A., D, W.C., Harrop, J.S., Aarabi, B., Shaffrey, C., Dvorak, M., Fisher, C., Arnold, P., Massicotte, E.M., Lewis, S., and Rampersaud, R. (2012). Early versus delayed decompression for traumatic cervical spinal cord injury: results of the Surgical Timing in Acute Spinal Cord Injury Study (STASCIS). PloS One 7, e32037.

9. Vaccaro, A.R., Daugherty, R.J., Sheehan, T.P., Dante, S.J., Cotler, J.M., Balderston, R.A., Herbison, G.J., and Northrup, B.E. (1997). Neurologic outcome of early versus late surgery for cervical spinal cord injury. Spine 22, 2609-2613.

10. Vale, F.L., Burns, J., Jackson, A.B., and Hadley, M.N. (1997) Combined medical and surgical treatment after acute spinal cord injury: results of a prospective pilot study to assess the merits of aggressive medical resuscitation and blood pressure management. J. Neurosurg. 87, 239-246.

11. Dvorak, M.F., Noonan, V.K., Fallah, N., Fisher, C.G., Finkelstein, J., Kwon, B.K., Rivers, C.S., Ahn, H., Paquet, J., Tsai, E.C., Townson, A., Attabib, N., Bailey, C.S., Christie, S.D., Drew, B., Fourney, D.R., Fox, R., Hurlbert, R.J., Johnson, M.G., Linassi, A.G., Parent, S., and Fehlings, M.G. (2015). The influence of time from injury to surgery on motor recovery and length of hospital stay in acute traumatic spinal 
cord injury: an observational Canadian cohort study. J. Neurotrauma 32, 645-654.

12. Feng, G., Hong, Y., Li, L., Liu, H., Pei, F., Song, Y., Huang, F., Tu, C., Li, T., Gong, Q., Liu, L., Zeng, J., Kong, Q., and Gupte, M. (2012). Anterior decompression and nonstructural bone grafting and posterior fixation for cervical facet dislocation with traumatic disc herniation. Spine 37, 2082-2088.

13. Krengel, W.F. 3rd, Anderson, P.A., and Henley, M.B. (1993). Early stabilization and decompression for incomplete paraplegia due to a thoracic-level spinal cord injury. Spine 18, 2080-2087.

14. La Rosa, G., Conti, A., Cardali, S., Cacciola, F., and Tomasello, F (2004). Does early decompression improve neurological outcome of spinal cord injured patients? Appraisal of the literature using a metaanalytical approach. Spinal Cord 42, 503-512.

15. Lenehan, B., Fisher, C.G., Vaccaro, A., Fehlings, M., Aarabi, B., and Dvorak, M.F. (2010). The urgency of surgical decompression in acute central cord injuries with spondylosis and without instability. Spine 35 (21 Suppl), S180-S186.

16. Levi, L., Wolf, A., Rigamonti, D., Ragheb, J., Mirvis, S., and Robinson, W.L. (1991). Anterior decompression in cervical spine trauma: does the timing of surgery affect the outcome? Neurosurgery 29, 216 222.

17. Liu, Y., Shi, C.G., Wang, X.W., Chen, H.J., Wang, C., Cao, P., Gao, R., Ren, X.J., Luo, Z.J., Wang, B., Xu, J.G., Tian, J.W., and Yuan, W. (2015). Timing of surgical decompression for traumatic cervical spinal cord injury. Int. Orthop. 39, 2457-2463.

18. McAfee, P.C., Bohlman, H.H., Ducker, T.B., Zeidman, S.M., and Goldstein, J.A. (1995). One-stage anterior cervical decompression and posterior stabilization. A study of one hundred patients with a minimum of two years of follow-up. J. Bone Joint Surg. Am. 77, 17911800 .

19. Schlegel, J., Bayley, J., Yuan, H., and Fredricksen, B. (1996). Timing of surgical decompression and fixation of acute spinal fractures. J. Orthop. Trauma 10, 323-330.

20. Umerani, M.S., Abbas, A., and Sharif, S. (2014). Clinical outcome in patients with early versus delayed decompression in cervical spine trauma. Asian Spine J. 8, 427-434.

21. van Middendorp, J.J., Hosman, A.J., and Doi, S.A. (2013). The effects of the timing of spinal surgery after traumatic spinal cord injury: a systematic review and meta-analysis. J. Neurotrauma 30, 1781-1794.

22. Wang, Q., Xiang, L., and Liu, J. (2013). Re: Feng G, Hong Y, Li L, et al. Anterior decompression and nonstructural bone grafting and posterior fixation for cervical facet dislocation with traumatic disc herniation. Spine (Phila Pa 1976) 38, 967.

23. Wilson, J.R., Tetreault, L.A., Kwon, B.K., Arnold, P.M., Mroz, T.E., Shaffrey, C., Harrop, J.S., Chapman, J.R., Casha, S., Skelly, A.C., Holmer, H.K., Brodt, E.D., and Fehlings, M.G. (2017). Timing of decompression in patients with acute spinal cord injury: a systematic review. Global Spine J. 7, 95s-115s.

24. Cadotte, D.W., Singh, A., and Fehlings, M.G. (2010). The timing of surgical decompression for spinal cord injury. F1000 Med. Rep. 2, 67.

25. Mattiassich, G., Gollwitzer, M., Gaderer, F., Blocher, M., Osti, M., Lill, M., Ortmaier, R., Haider, T., Hitzl, W., Resch, H., and AschauerWallner, S. (2017). Functional outcomes in individuals undergoing very early $(<5 \mathrm{~h})$ and early (5-24h) surgical decompression in traumatic cervical spinal cord injury: analysis of neurological improvement from the Austrian Spinal Cord Injury Study. J. Neurotrauma 34, 3362-3371.

26. El Tecle, N.E., Dahdaleh, N.S., and Hitchon, P.W. (2016). Timing of surgery in spinal cord injury. Spine 41, E995-E1004.

27. Dvorak, M.F., Fisher, C.G., Fehlings, M.G., Rampersaud, Y.R., Oner, F.C., Aarabi, B., and Vaccaro, A.R. (2007). The surgical approach to subaxial cervical spine injuries: an evidence-based algorithm based on the SLIC classification system. Spine 32, 2620-2629.

28. Aarabi, B., Sansur, C.A., Ibrahimi, D.M., Simard, J.M., Hersh, D.S., Le, E., Diaz, C., Massetti, J., and Akhtar-Danesh, N. (2017). Intramedullary lesion length on postoperative magnetic resonance imaging is a strong predictor of ASIA Impairment Scale grade conversion following decompressive surgery in cervical spinal cord injury. Neurosurgery 80 , $610-620$.

29. American Spinal Injury Association. (1992). International Standards for Neurological and Functional Classification of Spinal cord injury. ASIA/IMSOP: Chicago.

30. Boakye, M., Arrigo, R.T., Kalanithi, P.S., and Chen, Y.R. (2012). Impact of age, injury severity score, and medical comorbidities on early complications after fusion and halo-vest immobilization for C2 fractures in older adults: a propensity score matched retrospective cohort study. Spine 37, 854-859.

31. Ditunno, J.F. Jr., Young, W., Donovan, W.H., and Creasey, G. (1994). The international standards booklet for neurological and functional classification of spinal cord injury. American Spinal Injury Association. Paraplegia 32, 70-80.

32. Furlan, J.C., Fehlings, M.G., Massicotte, E.M., Aarabi, B., Vaccaro, A.R., Bono, C.M., Madrazo, I., Villanueva, C., Grauer, J.N., and Mikulis, D. (2007). A quantitative and reproducible method to assess cord compression and canal stenosis after cervical spine trauma: a study of interrater and intrarater reliability. Spine 32 , 2083-2091.

33. Furlan, J.C., Kailaya-Vasan, A., Aarabi, B., and Fehlings, M.G. (2011). A novel approach to quantitatively assess posttraumatic cervical spinal canal compromise and spinal cord compression: a multicenter responsiveness study. Spine 36, 784-793.

34. Vaccaro, A.R., Koerner, J.D., Radcliff, K.E., Oner, F.C., Reinhold, M., Schnake, K.J., Kandziora, F., Fehlings, M.G., Dvorak, M.F., Aarabi, B., Rajasekaran, S., Schroeder, G.D., Kepler, C.K., and Vialle, L.R. (2015). AOSpine subaxial cervical spine injury classification system. Eur. Spine J. 25, 2173-2184.

35. Miyanji, F., Furlan, J.C., Aarabi, B., Arnold, P.M., and Fehlings, M.G. (2007). Acute cervical traumatic spinal cord injury: MR imaging findings correlated with neurologic outcome-prospective study with 100 consecutive patients. Radiology 243, 820-827.

36. MIEMSS (2015). Maryland Institute for Emergency Medical Services Systems. https://www.nremt.org/rwd/public/states/state-ems-agencies/ mol (last accessed October 2018).

37. Aarabi, B., Alexander, M., Mirvis, S.E., Shanmuganathan, K., Chesler, D., Maulucci, C., Iguchi, M., Aresco, C., and Blacklock, T. (2011). Predictors of outcome in acute traumatic central cord syndrome due to spinal stenosis. J. Neurosurgery. Spine 14, 122-130.

38. Le, E., Aarabi, B., Hersh, D.S., Shanmuganathan, K., Diaz, C., Massetti, J., and Akhtar-Danesh, N. (2015). Predictors of intramedullary lesion expansion rate on MR images of patients with subaxial spinal cord injury. J. Neurosurgery. Spine, 1-11.

39. Aarabi, B., Simard, J.M., Kufera, J.A., Alexander, M., Zacherl, K.M., Mirvis, S.E., Shanmuganathan, K., Schwartzbauer, G., Maulucci, C.M., Slavin, J., Ali, K., Massetti, J., and Eisenberg, H.M. (2012). Intramedullary lesion expansion on magnetic resonance imaging in patients with motor complete cervical spinal cord injury. J. Neurosurg. Spine 17, 243-250.

40. White, A.A. 3rd and Panjabi, M.M. (1984). The role of stabilization in the treatment of cervical spine injuries. Spine 9, 512-522.

41. Vaccaro, A.R., Hulbert, R.J., Patel, A.A., Fisher, C., Dvorak, M., Lehman, R.A., Jr., Anderson, P., Harrop, J., Oner, F.C., Arnold, P., Fehlings, M., Hedlund, R., Madrazo, I., Rechtine, G., Aarabi, B., and Shaninline, M.; Spine Trauma Study Group. (2007). The subaxial cervical spine injury classification system: a novel approach to recognize the importance of morphology, neurology, and integrity of the disco-ligamentous complex. Spine 32, 2365-2374.

42. Bracken, M.B., Shepard, M.J., Collins, W.F., Holford, T.R., Young, W., Baskin, D.S., Eisenberg, H.M., Flamm, E., Leo-Summers, L., Maroon, J., et al. (1990). A randomized, controlled trial of methylprednisolone or naloxone in the treatment of acute spinal-cord injury. Results of the Second National Acute Spinal Cord Injury Study. N. Engl. J. Med. 322, 1405-1411.

43. Hurlbert, R.J., Hadley, M.N., Walters, B.C., Aarabi, B., Dhall, S.S. Gelb, D.E., Rozzelle, C.J., Ryken, T.C., and Theodore, N. (2013). Pharmacological therapy for acute spinal cord injury. Neurosurgery 72 Suppl 2, 93-105.

44. Raftery, A.E. (1995). Bayesian model selection in social research. Sociol. Method. 25, 111-163.

45. Harris, J.H., Jr., Edeiken-Monroe, B., and Kopaniky, D.R. (1986). A practical classification of acute cervical spine injuries. Orthop. Clin. North Am. 1, 15-30.

46. Allen, B.L. Jr., Ferguson, R.L., Lehmann, T.R., and O'Brien, R.P. (1982). A mechanistic classification of closed, indirect fractures and dislocations of the lower cervical spine. Spine 7, 1-27.

47. Fairholm, D.J. and Turnbull, I.M. (1971). Microangiographic study of experimental spinal cord injuries. J. Neurosurg. 35, 277-286.

48. Dohrmann, G.J., Wagner, F.C. Jr., and Bucy, P.C. (1971). The microvasculature in transitory traumatic paraplegia. An electron microscopic study in the monkey. J. Neurosurg. 35, 263-271. 
49. Dohrmann, G.J., Wagner, F.C. Jr., and Bucy, P.C. (1972). Transitory traumatic paraplegia: electron microscopy of early alterations in myelinated nerve fibers. J. Neurosurg. 36, 407-415.

50. Dolan, E.J. and Tator, C.H. (1982). The effect of blood transfusion, dopamine, and gamma hydroxybutyrate on posttraumatic ischemia of the spinal cord. J. Neurosurg. 56, 350-358.

51. Hall, E.D. and Wolf, D.L. (1986). A pharmacological analysis of the pathophysiological mechanisms of posttraumatic spinal cord ischemia. J. Neurosurg. 64, 951-961.

52. Locke, G.E., Yashon, D., Feldman, R.A., and Hunt, W.E. (1971) Ischemia in primate spinal cord injury. J. Neurosurg. 34, 614-617.

53. Young, W., Flamm, E.S., Demopoulos, H.B., Tomasula, J.J., and DeCrescito, V. (1981). Effect of naloxone on posttraumatic ischemia in experimental spinal contusion. J. Neurosurg. 55, 209-219.

54. Simard, J.M., Tsymbalyuk, O., Ivanov, A., Ivanova, S., Bhatta, S., Geng, Z., Woo, S.K., and Gerzanich, V. (2007). Endothelial sulfonylurea receptor 1-regulated NC Ca-ATP channels mediate progressive hemorrhagic necrosis following spinal cord injury. J. Clin. Invest. $117,2105-2113$

55. Simard, J.M., Woo, S.K., Norenberg, M.D., Tosun, C., Chen, Z., Ivanova, S., Tsymbalyuk, O., Bryan, J., Landsman, D., and Gerzanich, V. (2010). Brief suppression of Abcc 8 prevents autodestruction of spinal cord after trauma. Sci. Transl. Med. 2, 28ra29.

56. Balentine, J.D. (1978). Pathology of experimental spinal cord trauma. I. The necrotic lesion as a function of vascular injury. Lab. Invest. 39, 236-253.

57. Talbott, J.F., Whetstone, W.D., Readdy, W.J., Ferguson, A.R., Bresnahan, J.C., Saigal, R., Hawryluk, G.W., Beattie, M.S., Mabray, M.C., Pan, J.Z., Manley, G.T., and Dhall, S.S. (2015). The Brain and Spinal Injury Center score: a novel, simple, and reproducible method for assessing the severity of acute cervical spinal cord injury with axial T2-weighted MRI findings. J Neurosurg Spine 23, 495-504.

58. Mihai, G., Nout, Y.S., Tovar, C.A., Miller, B.A., Schmalbrock, P., Bresnahan, J.C., and Beattie, M.S. (2008). Longitudinal comparison of two severities of unilateral cervical spinal cord injury using magnetic resonance imaging in rats. J. Neurotrauma 25, 1-18.

59. Nout, Y.S., Mihai, G., Tovar, C.A., Schmalbrock, P., Bresnahan, J.C., and Beattie, M.S. (2009). Hypertonic saline attenuates cord swelling and edema in experimental spinal cord injury: a study utilizing magnetic resonance imaging. Crit. Care Med. 37, 2160-2166.

60. Salegio, E.A., Bresnahan, J.C., Sparrey, C.J., Camisa, W., Fischer, J., Leasure, J., Buckley, J., Nout-Lomas, Y.S., Rosenzweig, E.S., Moseanko, R., Strand, S., Hawbecker, S., Lemoy, M.J., Haefeli, J., Ma, X., Nielson, J.L., Edgerton, V.R., Ferguson, A.R., Tuszynski, M.H., and Beattie, M.S. (2016). A unilateral cervical spinal cord contusion injury model in non-human primates (Macaca mulatta). J. Neurotrauma 33, 439-459.

61. Hackney, D.B., Ford, J.C., Markowitz, R.S., Hand, C.M., Joseph, P.M., and Black, P. (1994). Experimental spinal cord injury: MR correlation to intensity of injury. J. Comput. Assist. Tomog. 18, 357-362.

62. Bilgen, M., Abbe, R., Liu, S.J., and Narayana, P.A. (2000). Spatial and temporal evolution of hemorrhage in the hyperacute phase of experimental spinal cord injury: in vivo magnetic resonance imaging. Magn. Reson. Med. 43, 594-600.

63. Fehlings, M.G., Tetreault, L.A., Wilson, J.R., Aarabi, B., Anderson, P., Arnold, P.M., Brodke, D.S., Burns, A.S., Chiba, K., Dettori, J.R., Furlan, J.C., Hawryluk, G., Holly, L.T., Howley, S., Jeji, T., KalsiRyan, S., Kotter, M., Kurpad, S., Marino, R.J., Martin, A.R., Massicotte, E., Merli, G., Middleton, J.W., Nakashima, H., Nagoshi, N., Palmieri, K., Singh, A., Skelly, A.C., Tsai, E.C., Vaccaro, A., Yee, A. and Harrop, J.S. (2017). A clinical practice guideline for the management of patients with acute spinal cord injury and central cord syndrome: recommendations on the timing $(<I=24$ hours versus $>24$ hours) of decompressive surgery. Global Spine J. 7, 195s-202s.

64. Hakalo, J. and Wronski, J. (2004). [Importance of early operative decompression of spinal cord after cervical spine injuries]. Neurol. Neurochir. Pol. 38, 183-188.

65. Phang, I. and Papadopoulos, M.C. (2015). Intraspinal pressure monitoring in a patient with spinal cord injury reveals different intradura compartments: Injured Spinal Cord Pressure Evaluation (ISCoPE) Study. Neurocrit. Care 23, 414-418.

66. Fehlings, M.G., Nakashima, H., Nagoshi, N., Chow, D.S., Grossman, R.G., and Kopjar, B. (2016). Rationale, design and critical end points for the Riluzole in Acute Spinal Cord Injury Study (RISCIS): a ran- domized, double-blinded, placebo-controlled parallel multi-center trial. Spinal cord 54, 8-15.

67. Grossman, R.G., Fehlings, M.G., Frankowski, R.F., Burau, K.D., Chow, D.S., Tator, C., Teng, A., Toups, E.G., Harrop, J.S., Aarabi, B., Shaffrey, C.I., Johnson, M.M., Harkema, S.J., Boakye, M., Guest, J.D., and Wilson, J.R. (2014). A prospective, multicenter, phase I matchedcomparison group trial of safety, pharmacokinetics, and preliminary efficacy of riluzole in patients with traumatic spinal cord injury. J. Neurotrauma 31, 239-255.

68. Casha, S., Zygun, D., McGowan, M.D., Bains, I., Yong, V.W., and Hurlbert, R.J. (2012). Results of a phase II placebo-controlled randomized trial of minocycline in acute spinal cord injury. Brain 135, 1224-1236.

69. Donnelly, J., Czosnyka, M., Adams, H., Robba, C., Steiner, L.A., Cardim, D., Cabella, B., Liu, X., Ercole, A., Hutchinson, P.J., Menon, D.K., Aries, M.J.H., and Smielewski, P. (2018). Pressure reactivitybased optimal cerebral perfusion pressure in a traumatic brain injury cohort. Acta Neurochir. Suppl. 126, 209-212.

70. Klein, S.P., Bruyninckx, D., Callebaut, I., and Depreitere, B. (2018). Comparison of intracranial pressure and pressure reactivity index obtained through pressure measurements in the ventricle and in the parenchyma during and outside cerebrospinal fluid drainage episodes in a manipulation-free patient setting. Acta Neurochir. Suppl. 126, 287-290.

71. Zeiler, F.A., Donnelly, J., Menon, D.K., Smielewski, P., Hutchinson, P.J.A., and Czosnyka, M. (2018). A description of a new continuous physiological index in traumatic brain injury using the correlation between pulse amplitude of intracranial pressure and cerebral perfusion pressure. J. Neurotrauma. 2018 Feb 9; Epub ahead of print.

72. Zeiler, F.A., Donnelly, J., Smielewski, P., Menon, D.K., Hutchinson, P.J., and Czosnyka, M. (2018). Critical thresholds of intracranial pressure-derived continuous cerebrovascular reactivity indices for outcome prediction in noncraniectomized patients with traumatic brain injury. J. Neurotrauma. 35, 1107-1115.

73. Huang, Y.M. and Davidsson, L. (2013). Sagging brain development after lumbar puncture agrees with Monro-Kellie hypothesis. J. Neurology 260, 920-922.

74. Karakis, I., Nuccio, A.H., Amadio, J.P., and Fountain, A.J. Jr. (2017). The Monro-Kellie doctrine in action: posterior reversible leukoencephalopathy syndrome caused by intracranial hypotension from lumboperitoneal shunt placement. World Neurosurg. 98, 868.e811-868.e815.

75. Mokri, B. (2001). The Monro-Kellie hypothesis: applications in CSF volume depletion. Neurology 56, 1746-1748.

76. Phang, I., Werndle, M.C., Saadoun, S., Varsos, G., Czosnyka, M., Zoumprouli, A., and Papadopoulos, M.C. (2015). Expansion duroplasty improves intraspinal pressure, spinal cord perfusion pressure, and vascular pressure reactivity index in patients with traumatic spinal cord injury: Injured Spinal Cord Pressure Evaluation Study. J. Neurotrauma $32,865-874$.

77. Aarabi, B., Hesdorffer, D.C., Ahn, E.S., Aresco, C., Scalea, T.M., and Eisenberg, H.M. (2006). Outcome following decompressive craniectomy for malignant swelling due to severe head injury. J. Neurosurgery $104,469-479$.

78. Albanese, J., Leone, M., Alliez, J.R., Kaya, J.M., Antonini, F., Alliez, B., and Martin, C. (2003). Decompressive craniectomy for severe traumatic brain injury: evaluation of the effects at one year. Crit. care Med. 31, 2535-2538.

79. Chibbaro, S. and Tacconi, L. (2007). Role of decompressive craniectomy in the management of severe head injury with refractory cerebral edema and intractable intracranial pressure. Our experience with 48 cases. Surg. Neurol. 68, 632-638.

80. Figaji, A.A., Fieggen, A.G., Argent, A.C., Le Roux, P.D., and Peter, J.C. (2008). Intracranial pressure and cerebral oxygenation changes after decompressive craniectomy in children with severe traumatic brain injury. Acta Neurochir. Suppl. 102, 77-80.

Address correspondence to:

Bizhan Aarabi, MD, FRCSC, FACS Department of Neurosurgery University of Maryland School of Medicine 22 South Greene Street, Suite S-12-D Baltimore, MD 21201

E-mail: baarabi@som.umaryland.edu 